\title{
LA RECONCEPTUALIZACIÓN CATÓLICA DE LA REVOLUCIÓN: EL PENSAMIENTO CRISTIANO FRENTE AL CAMBIO HISTÓRICO, CHILE (1960-1964)*
}

\author{
POR \\ MARCOS FERNÁNDEZ LABBÉ ${ }^{1}$ \\ Universidad Alberto Hurtado
}

\begin{abstract}
RESUMEN
El siguiente artículo busca, a partir de un conjunto de fuentes documentales destinadas a la esfera pública chilena, reconstituir históricamente e interpretar a partir del enfoque de la Historia Conceptual el uso dado por distintos agentes del pensamiento católico al concepto de revolución en Chile entre 1960 y 1964, subrayando los debates generados, los argumentos utilizados y su eficacia para la comprensión católica del cambio histórico en el periodo.
\end{abstract}

PALABRAS CLAVE: pensamiento católico; revolución; historia de Chile; historia conceptual.

\section{THE CATHOLIC RECONCEPTUALIZATION OF REVOLUTION: CHRISTIAN THOUGHT AND HISTORICAL CHANGE, CHILE (1960-1964)}

\begin{abstract}
This article analized and interpreted historically a set of Catholic Thought issues from the Conceptual History approach. It aims to highlight the use of concept revolution in Chile between 1960-1964, to examine controversies and arguments inside Catholic Church to faced the contingency of historical change.
\end{abstract}

KEY WORDS: Catholic thought; Revolution; Chilean history; Conceptual history.

COMO CITAR ESTE ARTículo / CITATION: Fernández Labbé, M. 2017. «La reconceptualización católica de la revolución: el pensamiento cristiano frente al cambio histórico, Chile (1960-1964)». Hispania Sacra 69, 140: 735-753. doi: 10.3989/hs.2017.046

Recibido/Received 16-10-2015

Aceptado/Accepted $\quad 09-01-2017$

\section{INTRODUCCIÓN}

Una de las características que describiría el comportamiento histórico de algunos conceptos centrales del vocabulario moderno -aquellos términos que usamos al referirnos a los fenómenos de la realidad y que poseen facultades descriptivas y prescriptivas sobre ésta- es

* Este artículo es resultado del proyecto FONDECYT regular № 1120251, "De la reforma a la solidaridad: vocabulario políticoconceptual de la Iglesia católica chilena, 1960-1985" y contó con la colaboración de Daniela Belmar, Pablo Geraldo, Javiera Letelier y Matías Placencio. Del mismo modo, agradezco de forma especial a todos aquellos que trabajan en la biblioteca de la Facultad de Teología de la Pontificia Universidad Católica de Chile por su excelente disposición.

${ }^{1}$ mfernand@uahurtado.cl / ORCID iD: http://orcid.org/0000-0003 $-0017-7378$ aquella referida a su temporalización, es decir, que son utilizados por los agentes sociales en el marco de la esfera pública y cargados de un horizonte de futuro improrrogable, conceptos-umbrales que deben de ser efectuados para poder dar coherencia al recorrido histórico que una determinada sociedad se representa como propio. ${ }^{2}$ Este es el caso del concepto de Revolución, que desde la última parte del siglo XVIII -y hasta quizás unos pocos años atrás- acaparó el imaginario y la praxis de multitud de sociedades y segmentos de éstas, ubicándose como una meta imprescindible de cruzar. La década de los 60 del siglo pasado fue una coyuntura en la que el poder de referencia de la Revolución tomó nuevos bríos, irrigándose sus significados hacia los más diversos campos de la vida social.

\footnotetext{
2 Koselleck 2009; Escudier 2010: 163-215; Bodeker 2009.
} 
El análisis histórico de este tipo de fenómenos ha sido alimentado en lo fundamental desde la perspectiva de la historia conceptual de matriz alemana (Begriffsgeschichte), pero que ha echado raíces en varias latitudes y particularmente en el mundo iberoamericano, en lo central por la iniciativa representada por Iberconceptos. ${ }^{3}$ Las proposiciones de la historia conceptual útiles para la investigación que aquí se presenta son varias, posibles de sistematizar así: junto a la noción de temporalización, la facultad de politización aparece también como relevante, en tanto un concepto al ser politizado lo que hace es convertirse en un arma de combate en el campo de la política, es decir, una herramienta que no posee un significado fijo, sino que es manipulado en función de la oposición a un adversario. De esa forma, revolución derivará en contra-revolución, o en el caso que aquí revisaremos, las acepciones de la revolución serán una y otra vez acomodadas para hacer referencia a los principios de un grupo determinado (los autores cristianos, por ejemplo), contra otros (los marxistas).

En segundo lugar, la noción de época-bisagra resulta también muy relevante para el contexto que aquí se analiza, en términos de que la década de los 60 fue comprendida por los agentes de pensamiento en los que se centra este artículo como una coyuntura de cambios de enorme gravedad, percibiéndola como una instancia de cambio histórico. ${ }^{4}$ Como se detalla más adelante, esta representación del cambio histórico estuvo marcada en el caso chileno por varias condiciones: el temor a que derivase en una situación revolucionaria violenta, la necesidad de que la mayor cantidad posible de actores sociales se sumara a los cambios, el impacto de estos presupuestos en el conjunto de las instituciones del país. A la larga, el periodo que aquí se estudia concluirá con la victoria electoral de una candidatura -Eduardo Frei Montalva como cabeza del Partido Demócrata Cristiano- que en gran medida se autorepresentaba como fundacional de una nueva época, con una retórica de "camino propio» entre el comunismo y el capitalismo liberal, y que le proponía a la sociedad chilena hacer una «Revolución en Libertad».

Dicho lo anterior, lo que este artículo se propone es revisar la reacción que sectores muy visibles del pensamiento católico chileno tuvieron ante la coyuntura de cambio histórico experimentada en el Chile de inicios de la década de 1960, particularmente la Compañía de Jesús, el Arzobispado de Santiago y agentes académicos vinculados a la Pontificia Universidad Católica de Chile. Para ello, ha resultado de enorme productividad el seguimiento conceptual del uso de Revolución en las fuentes que se citan, todas ellas elaboradas con vistas al debate público y en continúa circulación a lo ancho de la esfera pública chilena, esfera de la cual el catolicismo era un agente activo desde hacía mucho..$^{5}$ En tal sentido, la revolución puede entenderse como un factor semántico contingente imposible de obviar por la opinión católica, en tanto esta misma opinión estaba interesada en participar activamente de la discusión pública en torno a las necesidades y desafíos

\footnotetext{
3 Fernández Sebastiá (Director) 2009 y 2014.

4 Para el caso específico de la percepción del cambio histórico por parte del pensamiento católico al inicio de la década de 1960, Fernández $2016 a$.

5 Serrano 2003: 348.
}

que el país experimentaba. El conjunto del espacio político hacía suyas las proposiciones o divergencias en torno a la revolución, y por ello, la Iglesia Católica también debía hacerlo.

En ese camino, y es algo que debe atenderse desde un inicio, el rigor intelectual y la vocación polémica del pensamiento católico -particularmente entre los jesuitas residentes en Chile en el periodo- fueron excepcionales, motivando por ello un impacto en el espacio público que obliga a revisar las consideraciones comunes en torno al alcance de los procesos de secularización de cuño nor-atlántico en la experiencia histórica efectiva de una sociedad como la chilena de la segunda mitad del siglo $x \mathbf{x}{ }^{6}$ Fuera de ello, sin embargo, lo que aquí interesa resaltar es que el discurso católico -entendido como matriz discursiva capaz de promover significados a la vez que de movilizar prácticas capaces de modificar la realidad $-^{7}$ fue capaz tanto de entablar un debate público en torno a la significación profunda del concepto, como de albergar dentro de sí diversas reflexiones sobre el mismo, dando cuenta con ello de la relevancia que la revolución como tal mantenía en el periodo por su condición de umbral histórico, así como del dinamismo de un tipo de discurso que lejos de renunciar a la incidencia pública, lo que buscaba era orientar de forma eficiente los cambios estructurales que se juzgaban urgentes para Chile.

\section{PRIMEROS PASOS DE UNA CONCEPTUALIZACIÓN CATÓLICA DE LA REVOLUCIÓN: IDEAS Y PERCEPCIONES}

Es en este contexto de concurrencia de planos de transformación estructural de la vida histórica en la década de 1960 que el pensamiento y la opinión de inspiración católicas recurrirán al uso del concepto de revolución para dar cuenta no solo del temor generado por los cambios, sino también para calificar la acción política y social que los mismos cristianos debían emprender. A través de un arduo proceso de depuración conceptual y de auténtica politización -es decir, su uso en función del conflicto político contra otros participantes del campo semántico-histórico-, el vocabulario político católico se apropió significativamente del concepto de revolución, distinguiendo su propio uso del corrientemente asociado a la izquierda marxista. Un primer ejemplo de ello lo encontramos en las palabras de Enrique Alvear, redactor permanente del semanario del Arzobispado de Santiago de Chile, La Voz, quien a mediados de 1961 escribió "La Revolución de Cristo», breve columna en la que reconocía la inquina de una sociedad en la cual «una parte disfruta holgadamente de los bienes culturales y materiales y otra parte carece de lo necesario para el digno desarrollo de su personalidad", impidiendo con ello la paz, aunque este orden estuviese aceptado jurídicamente. A juicio de Alvear, el proceso de transformaciones experimentado en ese momento debía operar como la venida del mesías, en términos de "azotar con el temor de una gran revolución social en escala mundial», obligando por ello a los cristianos a convertirse en revolucionarios, empujándolos de forma

6 Los tópicos de este debate, centrado en América Latina y el mundo ibérico se pueden revisar en Gamper (Ed.) 2014; Stuven 2014.

7 Para una ampliación y discusión de esta definición Cabrera 2001. 
trascendente a que «nosotros empecemos la revolución y no la dejamos en manos del materialismo comunista». ${ }^{8}$

Muy similar asociación se planteaba poco más tarde en el mismo medio de prensa al comentar la iniciativa de la Alianza para el Progreso diseñada desde los Estados Unidos hacia América Latina, en tanto se recordaba la expresión de J.F. Kennedy de que a los cristianos «no les tiemblen las piernas con la palabra 'revolución', cuando ella significa una transformación a fondo de las condiciones existentes a fin de lograr, con el respeto del derecho y la dignidad del hombre, un mejor nivel de vida material y moral para todos los hombres». A juicio del director de la publicación, los cristianos no deseaban una revolución «que significa violencia, atropello de la justicia y de la persona, sangre y sacrificios inútiles e irracionales», sino otra, "bajo los imperativos de la justicia y la caridad cristianas». ${ }^{9}$ De forma manifiesta, la opción del Arzobispado era el apoyo y el atento análisis de las propuestas norteamericanas de contención del comunismo en el continente a través de la inversión y la reforma paulatina de las estructuras que agudizaban la pobreza y la exclusión.

El desarrollo de la tematización de Revolución, sin embargo, requirió de una serie de deslindes conceptuales cuya pista es interesante seguir aquí. Así, por ejemplo, para uno de los comentaristas de La Voz, la revolución en América Latina -a la luz de la experiencia cubana- poseía contenidos específicos de significación, asociados sistemáticamente con la necesidad de entenderla no como un mero "golpe de Estado", sino como una transformación profunda en el conjunto de las estructuras sociales; transformación la cual por su magnitud debía dejar de manifiesto «la fatalidad de la división social a la cual corresponde. No se puede hacer una revolución contra nadie; la revolución es contra un régimen, contra un estado de cosas y contra un sector numeroso y poderoso de personas que lo defienden.» Para el redactor, además, la revolución «supone que no hay otro camino; que el camino de la reforma legal es imposible o inútil; que el proceso democrático de formación de una opinión pública reformista es impracticable». ${ }^{10}$ Esta última frase puede ser interpretada en clave de política contingente, en tanto la vocación reformista del Partido Demócrata Cristiano chileno -una y otra vez relacionado por sus críticos con el medio de prensa del Arzobispado- se articulaba política y semánticamente a partir del distanciamiento de la significación corriente de Revolución, llegando a plantear como consigna central de su campaña presidencial en 1964 la «Revolución en Libertad».

Coherente con lo anterior, se consideraba en el número siguiente del semanario que la única posibilidad efectiva de que todo ello no se efectuase en "modo socialista» era «el cambio democrático de las instituciones y de los

8 Alvear, E. "La Revolución de Cristo», en La Voz, Semanario del Arzobispado de Santiago de Chile (en adelante LV), 23 de julio 1961, p. 3. El Semanario que citamos era el medio oficial del Arzobispado de Santiago, la diócesis más poblada del país así como su capital. Se vendía así en las distintas parroquias como en los establecimientos de periódicos de la ciudad, llegando a un tiraje de 15 mil ejemplares. Las temáticas que trataba superaban con mucho los solos aspectos religiosos, dedicando parte importante de sus páginas al comentario contingente nacional e internacional.

9 «Punta del Este», en LV, 13 de agosto 1961, p. 3.

10 LV, 13 de agosto 1961, p. 20. sistemas injustos», opción esta última con la cual el medio de prensa se comprometía. ${ }^{11}$ La necesidad de clarificación conceptual se prolongó por algunas semanas más, en tanto el mismo redactor se vio obligado a precisar sus definiciones, ejercicio el cual realizó convencionalmente a partir de la diferenciación con la revolución socialista, la que debido a su carácter "destructivo-constructivo» suponía necesariamente «el abandono por lo menos transitorio del régimen democrático de convivencia y el uso de la fuerza por el pueblo en rebelión, o en nombre del pueblo». Junto a ello, y de forma más relevante, el redactor se calificaba como «no-revolucionario» (en oposición a "antirrevolucionario»), por ser a su juicio la revolución un «sistema muchísimo más lento que una evolución verdaderamente rápida», en tanto esta última debía de ser capaz de acabar con las «condiciones previas» que hacían posible la revolución, ahorrándose así sus costos de violencia y conflictividad social. Sin embargo, y dicho lo anterior, el autor no dudó en definir a la revolución socialista como la "propia de nuestro tiempo», así como una "fuerza histórica» que movilizaba efectivamente a los agentes sociales. ${ }^{12}$

En un procedimiento de complejización del problema, el rechazo del senador democratacristiano Radomiro Tomic a la condena cerrada que La Voz hacía de la revolución cubana derivó en un intercambio epistolar interesante de reseñar aquí, en tanto que opuso criterios de definición semántica y consecuencias de acción política centrales para la comprensión cristiana de la revolución. Así, en primer lugar, Tomic asignaba un papel sintomático a la revolución cubana, que debía ser entendida como «una desviación -que debe ser analizada con rigurosa objetividad-de un proceso colosal que afectará el destino de la América entera en esta misma generación ${ }^{13}$, y que por lo tanto no podía ser analizada de forma simplista -como lo hacía La Voz al caracterizarla como «intrínsecamente perniciosa» en su deriva marxistaleninista- ${ }^{14}$, pues al hacerlo los cristianos corrían el riesgo de cometer el mismo tipo de error derivado del rechazo a la Revolución Francesa, es decir, la asociación a regímenes absolutistas de derecho divino y el distanciamiento de la democracia. A juicio de Tomic la realidad era más complicada, en tanto el proceso cubano estaba determinado por fuerzas exógenas de enorme relevancia -la agresión norteamericana y el bloqueo diplomático que proponían varios gobiernos latinoamericanos en ese momento-, y más allá de ello, dejaba en claro que la descomposición del capitalismo dependiente continental provocaba una «revolución indispensable», que en su opinión debía tematizarse como una "revolución cristiana», cuyo fundamento fuese "la defensa de la dignidad del hombre -particularmente de la dignidad de los pobres- mucho antes que la 'libertad de hacerse ricos' o de 'la propiedad privada de los medios de producción', que no eran 'instituciones sagradas' sino

11 LV, 20 de agosto 1961, p. 2.

12 LV, 27 de agosto 1961, p. 20.

13 Tomic, R. «Revolución con distingos y sin simplismos», en LV, 24 de diciembre 1961, p. 12. Radomiro Tomic (1914-1992) fue el candidato a la presidencia por el PDC en las elecciones de 1970 -en las que ganó la coalición de izquierda encabezada por Salvador Allende G.-, con un programa que profundizaba las reformas implementadas por la administración de Eduardo Frei Montalva.

14 LV, 17 de diciembre 1961, p. 3. 
situaciones contingentes sometidas al bien común». De tal modo, concluía el senador del PDC, «donde fracasen los cristianos, la revolución será marxista». Esta es para mí la mayor «lección de Cuba». ${ }^{15}$

Para los redactores del semanario, la respuesta a las definiciones de Tomic fue insistir en el carácter totalitario de la experiencia cubana, y con más detalle, considerar que la justificación de la revolución «como una manera de hacer resaltar la injusticia social y económica, aumenta la confusión», en tanto la "Iglesia chilena ha sido clara cuando ha condenado al régimen cubano». Para finalizar, $L a$ Voz coincidía en el aserto de Tomic de que donde fracasaran los cristianos la revolución sería marxista, pero manifestando su preferencia por «nuestro régimen de libertad y garantías, en el cual podemos luchar por esa revolución (cristiana), al sistema castrista en el cual el propio senador Tomic estaría encarcelado, desterrado o frente al paredón. En eso tiene Cuba un mérito positivo: mostrar lo que puede ser nuestro porvenir». ${ }^{16}$

Para Ismael Bustos (frecuente colaborador de la revista del PDC Política y Espíritu), por su parte, la discusión en torno a Revolución debía de instalarse en el campo más vasto de la filosofía de la historia, es decir, en términos de su comprensión como ritmo y significado del devenir temporal de la humanidad. En una clave cristiana y maritainista, Bustos señalaba en una reseña sobre el tema que a juicio de Jacques Maritain «lo mejor sería no soñar con una revolución cristiana sino esforzarse por introducir el ideal cristiano en las reformas que el mundo no comunista deberá realizar a fin de satisfacer a la justicia social». Es decir, el carácter reformista de la acción política democratacristiana se inscribía en la constatación del intelectual francés de que "ya es demasiado tarde para una revolución de tal tipo (moral), porque ya la revolución de nuestro tiempo se hizo, y no fue cristiana sino atea». Sin embargo, en un gesto relevante para nuestra discusión, el mismo Bustos matizaba la aseveración de Maritain al suponer que «allí donde reina aun claramente el imperialismo permanece abierta la posibilidad de una revolución cristiana». ${ }^{17}$

De opinión similar era Jacques Conchol -agrónomo de largo compromiso cristiano que se transformaría en ministro de agricultura del gobierno socialista de Salvador Allende a inicios de la década de 1970-, que invitado a exponer sobre "Los católicos y el cambio histórico» ante los miembros de la Parroquia Universitaria en 1962 expresaba frente a la pregunta de si este cambio sería «una Reforma o una Revolución", que lo que se esperaba de los católicos era que tuviesen una «actitud revolucionaria, qué duda cabe», palabras las cuales fueron apoyadas por un segundo expositor -el profesor de la Escuela de Derecho de la Universidad Católica Carlos Domínguez-, a juicio de quien la revolución debía desarrollarse «de acuerdo con una idea moral», justificando con ello la prescindibilidad de los «moldes jurídicos» en función de la naturaleza

15 Tomic, R. 1961: 12 .

16 "Nuestra respuesta a Tomic», en LV, 24 de diciembre 1961, p. 13. Un análisis detallado del anti-comunismo católico en el periodo en Fernández 2016c.

17 Bustos, I. "La Filosofía Maritainista de la Historia», en Política y Espíritu (en adelante PyE) 266, noviembre 1961, pp. 35-37. Sobre la influencia de J. Maritain en el continente, Compagnon 2009: 103-108. legitimante del cristianismo como factor de orientación revolucionaria. ${ }^{18}$

Misma convicción expresaba -en un contexto muy distinto- el dirigente del Centro Gremial Jesús Obrero, Luis Quiroga, quien tras la coordinación de 17 dirigentes de poblaciones «callampas» (chabolas) declaraba: «es necesaria una revolución que vaya a la transformación del espíritu de la gente; el marxismo pretende reformar solo las condiciones materiales en que se vive». ${ }^{19}$ En la misma clave, pero profundizando la naturaleza filosófica de su reflexión, un anónimo militante democratacristiano al mismo tiempo que se apartaba del marxismo por su crítica a la metafísica, reivindicaba ésta en tanto factor de una teoría revolucionaria cristiana, articulada a partir de una filosofía de la persona a la usanza de Maritain y Mouriac. La ausencia de una filosofía de este tipo impedía «justificar ni la sociedad comunitaria, ni la igualdad, ni los derechos, ni el progreso, ni siquiera el socialismo», y su presencia, por el contrario, permitía al cristiano «venir al mundo de la política y transformar la sociedad $» .{ }^{20}$ Así, un académico de leyes, un dirigente local y un intelectual cristiano llegaban a similares conclusiones: la inminencia del cambio, la urgencia de la acción y la oposición al comunismo como factores de conceptualización de Revolución.

En la misma senda se perfiló la lectura que la revista de la Compañía de Jesús en Chile, Mensaje, hizo de la Carta Pastoral de los Obispos chilenos referida a la actitud política y social que los cristianos debían tomar en el contexto preciso en que el país era percibido en 1962. Esa Carta definía un espacio de cambio urgente y que debía ser orientado explícitamente por la Jerarquía, como agente movilizador de las energías y capacidades de todos los católicos invertidas en la transformación estructural de Chile. Y al hacerlo, el editor de la revista jesuita recurrió al concepto de revolución, que "si no la hacemos nosotros, la 'revolución' vendrá pero no bajo el signo de la cruz, sino envuelta en roja bandera». ¿Significaba eso que los cristianos actuaban solo por temor al comunismo? No debía ser así, en tanto su acción transformadora debía operar «simplemente porque no podemos hacernos cómplices de la mentira, del egoísmo y de la injusticia». Una "auténtica revolución cristiana» era la que hacía «estallar viejos odres», la que cambiaría "radicalmente el estado actual de cosas». $Y$ en ese sentido, al igual que en la referencia antes citada, la diferenciación del comunismo era esencial, pues éste «solo cambiará una injusticia por otra. No habrá verdaderos cambios de estructuras sino de autoridades, la dictadura de los capitales se transformará en la dictadura del Estado". ${ }^{21}$

De ese modo, el contenido "revolucionario" de un documento episcopal se exaltaba en referencia no solo a la competencia semántica a la que hemos hecho alusión,

18 «Para Universitarios. Una parroquia revolucionaria», en LV, 6 de mayo 1962, p. 12.

19 «Pobladores cristianos, unidos harán fuerza», en LV, 10 de junio 1962, p. 11.

20 «Puntualización final», en PyE 272, mayo-junio 1962, pp. 43-44.

21 «Ecos de una Pastoral», en Mensaje (en adelante RM), 114, noviembre 1962, pp. 525-528. El texto de la Carta pastoral en http://documentos.iglesia.cl/ver_ficha.php?mod=documentos sini\&id=970\&sw_volver=yes\&descripcion=El\%20deber\%20social\%20 y\%20pol\%EDtico\%20en\%20la\%20hora\%20presente 
sino también como un ejemplo de los procedimientos políticos precisos que la voluntad de cambios mayoritario en la Jerarquía debía operar en los católicos. La mención de la revolución comunista como espectro -aun cuando no agotaba sus fuerzas en el anticomunismo tradicional- no buscaba su eliminación, sino su reemplazo. En el mismo número de noviembre de 1962 se publicaba un segundo artículo referido explícitamente a la Pastoral, esta vez redactado por el jesuita Mario Zañartu-doctor en economía por la Universidad de Columbia-, quien junto con anotar las críticas que el documento episcopal hacía del individualismo liberal, deslindaba la conceptualización marxista de la revolución de aquella que debía prevalecer en la actitud cristiana, evidenciando en primer lugar la existencia de "puntos concretos» entre ambas, y tras ello, los «males» de la "solución revolucionaria de tipo marxista», que pueden sintetizarse en lo siguiente: la frustración latente en el uso de la violencia cuando ésta no era visualizada con claridad en sus alcances, y se la asumía como «necesaria para cambiar las estructuras», es decir, como una suerte de dogma justificado solo por su imprescindibilidad; la objetivación de la acción revolucionaria en el «cambio de algunas estructuras y no de todas ellas», apelando con ello al reduccionismo economicista y anti-imperialista, pero sin modificar estructuras axiológicas, y por el contrario, despreciando los valores no económicos; la posibilidad de que las vanguardias revolucionarias perdiesen el control sobre sus actos, derivando en el sectarismo y la dependencia de intereses internacionales; la «mantención totalitaria» del proceso, en donde «los grupos dirigentes de la revolución marxista eternizan este proceso revolucionario y mantienen una organización política y económica en que no se respetan los derechos de todos, traicionando con esto la auténtica revolución social»; la glorificación esencialista y maniquea de la revolución como instancia definitiva de la vida y la historia, en términos de que «todo lo que está con ella es positivo, todo lo que no está con ella, está contra ella, y es por tanto negativo», llegándose "al simplismo de que todo era antes de la revolución perverso e inhumano y que con la revolución todos los problemas son automáticamente resueltos. Finalmente, lo que el autor denominó el 'exclusivismo del marxismo revolucionario', que suponía que eran las organizaciones marxistas las únicas capaces de guiar y aglutinar el proceso revolucionario, derivando por ello necesariamente en divisionismos y debilitamiento de la clase obrera». Así, todos estos elementos eran los que debían tener en cuenta aquellos «cristianos de avanzada para desconfiar de una revolución social de tipo comunista, como es concretamente preconizada en Chile y América Latina». ${ }^{22}$ En el fondo, el objetivo del artículo no era rechazar la posibilidad y pertinencia de una revolución, sino distinguir su acepción y práctica cristiana de aquella vigente y propia del marxismo.

La suma de los juicios antes comentados encontró una suerte de manifestación objetivable en el exhaustivo análisis referido a las percepciones en torno al cambio social en Chile, realizado por el sacerdote jesuita y sociólogo estadounidense Joseph Fichter, y que consultó el significado

22 Zañartu, M. "La Pastoral. Su contenido y reacciones», en RM 114, noviembre 1962, pp. 534-538. que los poco más de mil encuestados y encuestadas -todos definidos como "católicos nucleares»- daban a revolución. Así, para más del $60 \%$ era esperable «algún tipo de trastorno social en un futuro cercano», de los cuales un quinto preveía una revolución violenta y un $40 \%$ una de tipo pacífico, pero revolución al fin. ${ }^{23}$ En el grupo específico de los sacerdotes encuestados -que llegaban a 328-, el $60 \%$ creía en la inminencia de la revolución, de los cuales un $23,5 \%$ consideraba que sería violenta. ${ }^{24}$ Del mismo modo, del total de los informantes, el cuarto de las mujeres (de un total de 188) opinó en el mismo sentido, y menos del $20 \%$ de los varones consideró el carácter violento de la revolución como esperable. ${ }^{25}$ En términos etáreos, para el $28 \%$ de los más jóvenes encuestados, la revolución sería violenta ${ }^{26}$, en tanto que en los sacerdotes esta apreciación aumentaba con la edad, siendo los clérigos mayores quienes preveían un acontecimiento definido como violento. ${ }^{27} \mathrm{En}$ el fondo, los resultados de la investigación que reseñamos apuntaron hacia una consensuada percepción por parte de los católicos en torno a la inminencia de la revolución, el carácter así pacífico o violento que ésta tendría y el papel que en el cambio -y ante el cambio- debía jugar la Iglesia católica. Los dos últimos aspectos son ilustrativos del diagnóstico católico: era la "separación de clases» que caracterizaba a la sociedad chilena la que «puede finalmente definir la diferencia entre el cambio social ordenado y el trastorno social revolucionario", es decir, las causas profundas de la revolución eran de naturaleza estructural y no solo efecto de la agitación comunista (aun cuando el marxismo era un factor presente en la investigación y sus resultados). A partir de esa constatación estructural, Fichter recomendaba que para adaptar a la Iglesia a la transformación social, su papel debía estar «definido más por actitudes de los progresistas, que por las de los tradicionalistas». ${ }^{28}$

En una lógica muy similar, es relevante recordar aquí las opiniones que el joven estudiante de sociología de la Universidad Católica y futuro líder del Movimiento de Acción Popular Unitaria, MAPU -escisión de la Democracia Cristiana con un fuerte componente marxista fundado a fines de la década de 1960- Rodrigo Ambrosio entregaba a Política y Espíritu en 1962, centrándose su reflexión en la oportunidad de la revolución en Chile, en sus condiciones de operación y la actitud que frente a ella debían sostener los cristianos. Antes de proponer una normativa católica para la revolución política, lo que Ambrosio hacía era deslindar a la doctrina cristiana de la reflexión estrictamente política, en tanto el papel de la Iglesia católica era, doctrinalmente, orientar a los católicos en torno a «cuándo un sistema o estrategia política es acorde o no con la naturaleza humana», lo que era indicativo de que «es al nivel más profundo de los principios $-y$ no al nivel de los sistemas- que la Iglesia se plantea la realidad política». En esa lógica, entonces, para el dirigente universitario la discusión en torno al marxismo o el liberalismo -tan presente en la Carta Pastoral de septiembre de 1962- era de alguna forma "falsa», en tanto "no existe

\footnotetext{
23 Fichter 1962.

24 Ibídem: 46.

25 Ibídem: 96.

26 Ibídem: 115.

27 Ibídem: 129.

28 Ibídem: 192 y 225.
} 
una correspondencia estricta entre la doctrina y el uso de ciertas herramientas políticas", radicando la decisión de estas últimas en el juicio de los laicos, y en relación a la contingencia en que se encontraran.

Esa decisión pragmática y situada era luego puesta en revisión a partir de la doctrina católica. En ese proceder, la inminencia de la revolución en América Latina era un hecho para el joven sociólogo, quien además consideraba que la hipótesis de la revolución convivía -especialmente en el caso chileno- con aquella asociada a la democracia formal y su capacidad para dar cuenta del cambio de estructuras que la realidad continental exigía. Ello provocaba una suerte de solución de continuidad entre la alternativa institucional y la revolucionaria, en tanto en un país como Chile "las estructuras y las fuerzas tradicionales son todavía fuertes, y si se cierran en sus posiciones regresivas, pueden provocar conflictos tan serios con las estructuras y fuerzas nuevas -cada vez más maduras- que seamos conducidos al terreno de otra hipótesis», es decir, de la revolución. En última instancia, de acuerdo a Ambrosio los cristianos -o si se prefiere el conjunto de la ciudadanía y sus instituciones- debían «tener imaginación y audacia para hacer posible la hipótesis de la democracia formal. Pero al mismo tiempo se debe ser realista para saber cuándo esta hipótesis resulta engañosa, ingenua, a contrapelo y entonces hay que tener tanta o más imaginación y audacia para trabajar dentro de la segunda hipótesis», es decir, nuevamente, la revolución.

De forma coherente, la reflexión de Ambrosio derivó hacia el problema de la violencia, que se encuadrará de modo preciso en la normativa doctrinal católica al respecto -dando cuenta por ello de las condiciones precisas para hacer de la violencia un acto legítimo (la tiranía, la búsqueda de un bien mayor, la imposibilidad de que se generasen consecuencias peores que el estado de cosas que se buscaba transformar, etc.)- pero que subrayará la idea de la responsabilidad social de la violencia: «no es el revolucionario el que violenta al sistema, sino el sistema el que violenta a la sociedad. El acto o actos de violencia se entienden, pues, como el medio por el cual la sociedad se libera de un estado de violencia». ${ }^{29}$ De ese modo, en la reflexión de un joven intelectual católico de inicios de la década de 1960 la articulación de la justificación de la violencia revolucionaria se encontraba irrigada de la doctrina tradicional de la Iglesia, no siendo así necesario desplazamiento alguno -desde esta perspectiva- para poder hacer, cristianamente, la revolución. Más todavía, en la segunda parte del artículo que citamos, Ambrosio tanto trascendentalizaba a la revolución en el orden escatológico del Reino y la esperanza, como advertía sobre la posibilidad de no lograr una revolución cristiana y sus salidas alternativas. En torno a esto último, la reflexión del autor es relevante, en tanto se «sobrepone» a la derrota terrenal en pos de un alcance sagrado de la acción política católica, un horizonte providencial:

Si fracasamos en la conquista del poder, si fracasamos o es imposible la colaboración, si fracasamos o es imposible la oposición legal o violenta, o sea si jugamos todas

\footnotetext{
${ }^{29}$ Ambrosio, R. «Medios políticos en América Latina», en PyE 276, noviembre 1962, pp. 43-48.
}

nuestras alternativas políticas y las perdemos $-\mathrm{y}$ ésta es una posibilidad que no podemos escamotear- ¿qué actitud tendremos? ¿Viviremos eternamente frustrados, miraremos el porvenir con escepticismo, juzgaremos a los que nos gobiernan con resentimiento? ¿lmitaremos al Ejército Secreto de Argelia en su penosa desesperación? No. Somos cristianos. No pecaremos contra la esperanza. Miraremos la historia con serenidad, sin amarguras, incluso, recordando que el Reino avanza por todos los caminos de la historia, con un alegre optimismo. Porque sabemos que los esquemas políticos triunfantes - los nuestros o los ajenos- perdurarán solo en lo que tienen de profundamente humano. Y tarde o temprano se abrirán a valores más complejos y más ricos. Entonces los cristianos tendrán de todas maneras una palabra que decir. ${ }^{30}$

De ese modo, la opción revolucionaria de los cristianos se amplificaba tanto hacia la trascendencia del orden providencial, como se subordinaba al resultado de la acción histórica contingente, relativizando de manera manifiesta ambos planos así reunidos en el campo de la acción política. ${ }^{31}$

Como hasta aquí se ha visto, en el pensamiento y la opinión católica de inicios de la década de 1960 existía la percepción de la inminencia del cambio histórico, que bien podía tomar la forma de la transformación revolucionaria. Frente a tal percepción se articulaban propuestas de semantización de la revolución que se anclaban en el rechazo al comunismo y la motivación que los laicos debían sostener para intervenir directamente en el cambio de estructuras. Con matices, la acepción cristiana de la revolución derivaba en la acción política y el debate temporal. Para afinar ese tipo de convicciones un más aplicado deslinde conceptual era indispensable. Esa tarea asumieron los jesuitas.

\section{LA REVOLUCIÓN EN MARCHA: LA CONCEPTUALIZACIÓN JESUITA EN LA CONTINGENCIA LATINOAMERICANA}

El hito quizás más relevante en la primera fase de la discusión conceptual en torno a revolución en los marcos de la reflexión cristiana fue la publicación de un número especial de la revista jesuita Mensaje a finales de 1962, y que fue inmediatamente saludada y criticada por los distintos agentes de opinión. Entre los primeros se encontraba $L a$ Voz, que a través de su director manifestaba su orgullo de que «este esfuerzo para actualizar el pensamiento cristiano frente al gran problema del continente, haya partido desde nuestra patria», y confiaba en que los contenidos ahí discutidos se oyesen «en toda la extensión americana, como una llamada a la acción inmediata».32 En lo específico, el número de Mensaje, publicado el último mes de 1962 bajo el concepto de «visión cristiana de la Revolución en América Latina», incluyó artículos de autores como los jesuitas Pierre Bigo, Robert Bosc, Roger Vekemans, Juan Luis Segundo, José Aldunate, Jean-Yves Calves y Gerardo Claps; y los profesionales Javier Lagarrigue, Alejandro Magnet, Betty Cabezas, Jacques Chonchol, Máximo Pacheco, Raúl Prebisch, Carlos Domínguez y Juan Pablo Terra.

\footnotetext{
30 Ambrosio, R. «Medios políticos en América Latina (2 parte)», en PyE 277, diciembre 1962-enero 1963, pp. 51-56.

31 Un análisis en profundidad en torno a las condiciones y espacios de politización de los laicos en el periodo en Fernández 2016b.

32 «Revolución en América Latina», en LV, 16 de diciembre 1962, p. 3.
} 
En su presentación - «Revolución en América Latina»-el editor iniciaba la discusión estableciendo que la revolución que vivía el continente ya no era de esas en las que solo "generales de anchos chambergos y vistosas condecoraciones arrebatan el poder a otros generales», como se tendía a conceptualizar los eventos «revolucionarios» antaño. No, en América Latina, «una inmensa y cada vez más creciente mayoría está tomando conciencia de su fuerza, de su miseria y de la injusticia del 'orden' político, jurídico, social y económico que se le obliga a aceptar», y que había encontrado en la revolución un arma suficiente para «adueñarse del poder para realizar un auténtico bien común». El punto era -para el redactor- que esta revolución se construía a partir de la «única ideología revolucionaria que se encuentra a su alcance: la ideología marxista». En la práctica ello derivaba en que la revolución no se agotaba en la lucha contra las injusticias, sino que se articulaba como un proceso de «violencia vengadora y vengativa, represalia, persecución, aplastamiento de libertades y derechos, paredón y exilio». Esta situación dividía las opiniones al interior de los cristianos, problematizaba la actitud de éstos frente la inminencia y actualidad del factor revolucionario, y con ello muchas veces lo simplificaba. Mensaje debía por tanto orientar a sus lectores, y para ello emprendía la tarea de debate y conceptualización de la Revolución en América Latina.

Así, y bajo el acápite "el concepto de Revolución», el editor distinguía en primer lugar entre los meros cuartelazos o insurrecciones y el contenido esencial de una auténtica revolución, que estaría dada por el "cambio de estructuras", y por ello, por su contenido «ideológico», entendido como «una programación de futuro y voluntad de realización». Por lo mismo, Revolución debía asociarse semánticamente a «reforma», anulando así la dicotomía entre «reforma o revolución», en tanto la "reforma» fuese «integral y radical», es decir, revolucionaria. Tal y como antes recordaba el sacerdote Zañartu, las actitudes que la revolución -como condición ante la cual era inevitable posicionarse- gene-raba eran duales: una primera conceptualización de la actitud revolucionaria distinguía tanto el carácter objetivo de su inminencia -el orden capitalista y su poder de exclusión de las mayorías y con ello la generación de hondos resentimientos-, como su riesgo de ser manipulada y aprovechada de forma inescrupulosa por «el pequeño empleado, artista sin aplauso, profesional fracasado, intelectual sin eco», es decir, por segmentos no auténticamente populares pero profundamente resentidos.

Junto a esta actitud oportunista frente a la Revolución, la editorial de Mensaje destacaba el reverso inauténtico del "anti-revolucionario» que lo era no por la defensa de los derechos de los individuos o su honesta repulsa al cambio social, sino por la sola y mezquina protección de sus propios intereses, es decir, del egoísmo que una y otra vez la crítica católica al capitalismo evidenció como causal de la posibilidad revolucionaria, particularmente visible en el contexto político de un gobierno de derechas y con vocación tecnocrática como fue el de Jorge Alessandri Rodríguez, entre 1958 y 1964. Ante la dual inautenticidad, el editor desarrollaba la que a su juicio debía ser la actitud cristiana, es decir, auténtica. Ella debía estar fundada en la verdad, a partir de un "juicio objetivo», distante tanto de "embestir contra molinos de viento" como de "ocultar la cabeza como el avestruz de la fábula. Ni ilusionismo ingenuo ni realismo miedoso». Ante "la revolución en marcha, es imposible permanecer neutral» se afirmaba, y ello obligaba al cristiano a recordar, primero, que el mismo cristianismo «fue una revolución pero, no lo olvidemos, promovida por un amor invencible». La revolución vigente, por su parte, impedía conciliar "una actitud auténticamente cristiana con una actitud cerradamente anti-revolucionaria», debiendo a su juicio privilegiarse el esfuerzo de dirigir la «revolución en marcha» por "canales cristianos", sustentados por la convicción de la fraternidad de los hombres y la urgencia de «instaurar un régimen político, un orden jurídico, social y económico que realice efectivamente el bien común, el bien de todos, aunque tengamos que sacrificar ciertos bienes particulares». Para Mensaje, «el cristiano -hijo de la esperanza-tiene la obligación de esforzarse por 'cristianizar' la venidera revolución, de canalizarla por canales humanos, de despojarla de venganza, de resentimiento, de ambición, de lucro, de violencia, de injusticia», significando ello reconocer los riesgos que la promoción de la revolución significaba -en tanto «nadie puede saber exactamente dónde termina la revolución»-, pero "la vida es riesgo y el cristianismo no es una religión de seguridades muelles sino de generosas locuras». Así, audacia, verdad y unidad en Cristo eran los caminos que el cristiano debía seguir para hacer posible aquello que operaba, a fin de cuentas, como razón de fondo para la argumentación jesuita: existía la posibilidad de cristianizar la revolución «en marcha». ${ }^{33}$

En una senda muy similar, el artículo del jesuita Pierre Bigó sostenía en lo central que las revoluciones hasta ahora realizadas -la liberal y la marxista- no eran sino "herejías cristianas», incapaces de dar al hecho revolucionario la profundidad que la «verdadera» revolución cristiana tenía. Por eso era América Latina -y no África o Asia- en donde la revolución florecía, en lo fundamental por su tradición cristiana y su realidad de subdesarrollo. ${ }^{34}$ Cambiando el

33 «Revolución en América Latina», en RM 115, diciembre 1962, pp. 9-12. Anexo a la editorial se incluía un glosario, que buscando precisar la terminología distingue entre Cuartelazo, Golpe de Estado, Insurrección, Revuelta, Subversión, Sedición, Evolución, Reforma y Revolución, definiendo esta última así: «es un cambio deliberadamente producido, responde a una ideología, a una planificación, es rápido y radical y se refiere a todas las estructuras básicas (políticas, jurídicas, sociales y económicas); cambio, por consiguiente, rápido, profundo y global de las estructuras vigentes. La revolución puede ir acompañada de insurrección pero no necesariamente lo es. En la revolución debemos distinguir dos momentos y dos ritmos: a) el momento de la ruptura radical con las estructuras vigentes, b) el momento de la elaboración del orden nuevo. La ruptura se presenta siempre con carácter de rapidez; es casi un corte en la historia, un borrar el pasado y re-empezar. La elaboración del orden futuro solo puede ser relativamente rápida. Lo importante es que esta preparación del orden futuro no se paralice transformándose en una provisoriedad (sic) definitiva. En este caso la revolución habría fracasado como 'revolución'. Siendo la revolución esencialmente un 'cambio', lógicamente termina con la instauración del 'nuevo orden', p. 13».

34 «El socialismo marxista, al igual que el liberalismo revolucionario, nacieron ambos en un mundo cristiano, son parte de él. Ni el islam ni las demás religiones no cristianas hubiesen proporcionado el terreno en que se desarrollaron. Pero al mismo tiempo estos sistemas desgarran el mundo cristiano. Están fundamentados en afirmaciones cristianas -afirmaciones de libertad y de justicia- pero estas afirmaciones están incluidas en negaciones que las desfiguran y, al fin de cuentas, las destrozan». Bigó, P. «Cristianismo y Revolución en la época contemporánea», en RM 115, diciembre 1962, pp. 14-24. 
foco hacía el plano de la decisión moral, el artículo que redactó el sacerdote jesuita y profesor de Teología Moral de la Facultad de Teología de la Pontificia Universidad Católica José Aldunate explicitaba los tres factores presentes en toda situación revolucionaria, que eran los que obligaban al posicionamiento de los cristianos: la «inadecuación de las estructuras y de la misma autoridad social con respecto a las exigencias del 'bien común'; la «resistencia al cambio por parte de esas estructuras» y «el movimiento que tiende a imponer los cambios que se estiman necesarios». A su juicio, quienes ejercían la última función eran las masas populares, que rompían "las relaciones normales de subordinación», justamente a causa de la inadecuación de las estructuras de organización social para alcanzar el «bien común».

En este sentido, es interesante la distinción que el jesuita Aldunate hacía entre una situación revolucionaria auténtica y otra que no lo era, en donde la primera era producto de "una real inadecuación sustancial e insuperable (dentro del orden existente) entre las estructuras o la autoridad (que es una de ellas) y el bien común»; en tanto que la segunda se basaba «no de una tal inadecuación objetiva sino de un falso ideal de bien común, una falsa ideología en las masas, que se quiere imponer a las autoridades imperantes». El efecto de esto era la necesidad de calificar la revolución solo luego de su concreción, y su concreción era «ruptura radical e integral del orden existente». Así, a su juicio la responsabilidad moral -y por ello política- del cristiano era trabajar "por la reforma de las estructuras», con el fin de "readaptarlas y reorientarlas nuevamente en vistas del bien común», corrigiendo así la inadecuación que justificaba la revolución, recuperando «una estructuración sana y equilibrada de la sociedad». Los caminos para esta tarea eran dos: «reformar ante todo la cabeza, la estructura política y la legislación», es decir, operar a partir del gobierno en la persecución de la restitución del bien común; "o bien obrar directamente sobre las estructuras de base o crear las necesarias y convenientes si no existen», aplicando para ello el principio de la subsidiariedad, preferido según el autor por la filosofía cristiana, aunque muy escaso en el continente latinoamericano.

En síntesis, la adecuación de las estructuras a las finalidades del bien común podría ser tarea delasinstituciones de gobierno, obviando gracias a ello la revolución. Pero si estas instituciones "son rígidas e irreformables, y el bien común sigue urgiendo una restructuración, entonces para el cristiano, en la imposibilidad de la reforma pacífica y legal, se plantea el problema de la licitud de una revolución incluso violenta $y$, por lo menos inicialmente, ilegal». ${ }^{35}$ Antes de evaluar este problema -que será central para la reflexión católica en todo el continente y que desde aquí en adelante marcará a fuego la resistencia al concepto revolución o su adopción integral por parte de sectores del pensamiento y la acción social y política de inspiración cristiana- ${ }^{36}$, el mismo Aldunate argumentaba el porqué de la opción cristiana por la reforma antes que por la revolución, estableciendo en lo central la necesidad y valor de la «continuidad, confianza, unidad» para la vida social, que la revolución hace «estallar»,

35 Aldunate, J. «El deber moral ante la situación revolucionaria», en RM 112, diciembre 1962, pp. 87-95.

36 Löwy 1999. deshaciéndose en ello su único valor: «el valor de la unidad social». La metáfora patológica era esta vez recurrida por su poder gráfico: «es delicado mutilar un miembro vivo en un organismo, por enfermo que esté, pues alrededor de él se han creado tantas vinculaciones, interdependencias, funciones.» Era mejor "la reforma agraria a la agitación campesina, la reforma gradual y silenciosa de las costumbres a los choques y escándalos ruidosos».

En esta misma línea de argumentación, Aldunate desarrolló una coda en su artículo referida a la autoridad como principio básico de la articulación social, en tanto «más sufriría el bien común por la no obediencia que por los efectos de una mala política, pues la desobediencia compromete, no cualquier estructura, sino una de las más fundamentales que es la del respeto a la autoridad como tal». El problema, evidentemente, se desplegaba cuando esa autoridad legítima obstaculizaba el bien común e incapacitaba a los ciudadanos para reformarla legalmente. Porque así como no era deseable la violencia y destrucción de la unidad social provocada por la revolución, tampoco lo era que el cristiano se inscribiese como "artífice o cooperador en la injusticia o inmoralidad», ante lo cual su «deber es negarse». Para cerrar su argumento, el teólogo recordaba definiciones propias de otros contextos, en donde el problema de la tiranía fue tematizado como justificación de la rebelión, en tanto «si la autoridad se convierte en un injusto agresor contra la sociedad misma que debía servir, la sociedad tiene derecho a una legítima defensa»; cosa similar a lo sucedido "si la autoridad se desvanece, si sus representantes se hacen indignos de ella y traicionan en lo fundamental su función», volviendo con ello la autoridad "sobre la nación en su conjunto o sobre sus grupos realmente representativos, que pueden ocupar el poder».

Fuera de esas instancias límites -la tiranía o la disolución espontánea de la autoridad-, la pregunta en torno a la licitud de la revolución sobre la reforma y el uso sistemático de la violencia revolucionaria quedaba ajustada a su condición de «medida última que se toma, agotados los medios pacíficos», siempre y cuando los males que remediase fueran mayores que los que provocaba, y que "los medios empleados sean morales (o sea, no se comprometan valores fundamentales)». Estrictamente, además, en la opinión católica persistía el convencimiento de que «históricamente las revoluciones, en su conjunto, han traído más males que bienes a la sociedad». De igual modo, «mientras no se haya intentado sinceramente la reforma, no hay derecho a hacer una revolución». Sin embargo, y hechas todas las salvedades y cruzadas todas las etapas de reforma e inadecuación objetiva de las estructuras por la vía evolutiva, «el deber podrá señalar al ciudadano el camino de la revolución», y ante ello el jesuita y profesor de moral establecía una serie de advertencias o puntos a considerar.

En primer lugar el problema de la propiedad de los bienes debía, en un contexto revolucionario, ser reducido al principio de la "grave o extrema necesidad», que de manera individual justificaba la apropiación de bienes ajenos, y que a escala social «hace pasar a segundo término todo el régimen jurídico de bienes», siguiendo la lógica de que "la necesidad común prima sobre la necesidad particular y obliga a los sacrificios correspondientes». Así, el remedio 
de la "extrema necesidad» generaba «la obligación moral que tiene cada uno, conforme a su posibilidad social, de promover estos necesarios cambios de estructuras». En tal sentido, al preguntarse por quiénes debían hacer la revolución, Aldunate no dudaba en asignar tal responsabilidad, en primer lugar, a los gobiernos, en tanto eran tales instituciones las que, ante la persistencia de la inequidad y los obstáculos al bien común debidos a la inadecuación de las estructuras, «deberán hacerlas estallar y reemplazar por otras. El gobierno saldrá con esto de la legalidad pero no de la legitimidad: será siempre autoridad legítima y auténtico artífice del bien común». Dicho esto, el sacerdote exponía la obligatoriedad de que "todos los ciudadanos» participasen de la revolución, en tanto era responsabilidad de todos la construcción del bien común, y por ello la pertinencia de labores de preparación y apoyo de la revolución «cada uno desde su esfera de influencia», llegando incluso algunos "eventualmente a actuar en ella», en especial los militares, que son «mano ejecutora y no cabeza».

Hechas así las distinciones y asignadas las responsabilidades conceptuales y de posición, el problema de la revolución volvía a ser planteado por Aldunate en el plano de la experiencia específica de los sujetos reales, ante cada «hombre, con su conciencia cristiana». En esta dimensión, el sacerdote recomendaba lo que podemos denominar como una vía de politización objetiva, en términos de que planteaba la imposibilidad para el cristiano de "hacerse cómplice de la injusticia social de la situación o de la estructura en que me encuentro", por lo que se debía reconocer y comprometer con la «verdadera exigencia del bien común sin romper los verdaderos valores de mis vinculaciones sociales», que por fuerza podían o debían adquirir una «expresión social» a partir de su articulación organizacional, que a fin de cuentas aparecía en el argumento del teólogo como la expresión externa de la «verdadera revolución», aquella que se efectuaba en el plano de «lo íntimo, lo personal, la reforma de los individuos», y que movilizaba a cada cristiano en una doble dimensión: la restaurativa (que Aldunate define como la efectivamente cristiana acepción de revolución), en términos de «volver a lo primero, al orden que Dios creó en un principio y que fue destruido por el pecado», pero que «restauró Cristo a partir de esa renovación del corazón»; y aquella propia del "terreno existencial», en tanto cada cristiano se obligaba «a un examen de la sociedad en que participa y actúa, para ser en ella fermento siempre presente y siempre transformador $» .{ }^{37}$ Así, y ya cerca de sus conclusiones, el moralista jesuita reunía dos factores de organización del pensamiento político católico que hemos seguido en esta sección: por un lado, la trascendentalización de un concepto secular como es el de revolución (de matriz astronómica antes que teológica) ${ }^{38}$, indicando con ello la comunicación efectiva entre el campo de la política y el del pensamiento doctrinario católico; y por otro, la necesidad y licitud de la acción política profana de parte de los cristianos y el abandono explícito de versiones contemplativas que sostuvieran la oposición acción en el mundo-experiencia religiosa.

Es en la definición precisa que la acción política así

37 Aldunate, J. «El deber moral ante la situación revolucionaria», en RM 112, diciembre 1962, pp. 87-95.

38 Arendt 2004: 25-77. objetivada supone que Aldunate sitúa la última parte de su reflexión, vehiculizada por la pregunta clave de cuál debía ser la actitud del cristiano con respecto a un movimiento revolucionario ya existente y, esperablemente, no inspirado por el pensamiento católico. La respuesta que el jesuita adelantó fue doble: el movimiento en cuestión debería ser enjuiciado «desde el punto de vista de los valores morales», y luego de ello, dando cuenta de la necesaria coherencia entre fines y medios, en tanto se evaluaría que "su fin sea bueno y que sus medios sean conducentes y legítimos». A partir de esta definición dual, el autor que seguimos propuso una escala de actitudes que iban desde la vinculación decidida con aquellos movimientos que presentasen «ideales sustancialmente buenos aunque quizás informes y medios de acción o programas concretos adecuados o al menos posibilidad de adoptarlos»; hasta la oposición «en toda línea» a aquellos que sustentaran «ideales falsos, respecto al hombre y la sociedad y medios eficaces para implantar esos ideales falsos». La posición intermedia estaba dada por el diálogo y no así la colaboración con propuestas continentes de «ideales sustancialmente buenos, pero medios o programas equivocados que no llevarán al verdadero bien común»; o la colaboración "en los objetivos concretos» sin compartir los fines de aquellos movimientos dotados de «ideales falsos, probablemente confusos, pero con medios que no llevan realmente a esos ideales, sino que responden a necesidades del momento».

De forma evidente, los resultados más visibles de toda la ecuación política presentada por Aldunate pueden sintetizarse en el hecho de la posibilidad necesaria de diálogo y colaboración con aquellos programas alineados con el bien común y la justicia de sus medios, y la oposición cerrada -ante los programas, no las personas, en tanto con éstas «siempre habrá una posibilidad de diálogo y colaboración»- hacia aquellos que se verificasen "con el error y la injusticia». Esta última afirmación se referenciaba en el texto del sacerdote específicamente hacia el comunismo, reconocido como el movimiento más peligroso, dada su "férrea y totalitaria» organización. Sin embargo, la definición final correspondía «exclusivamente al individuo, al ciudadano", no debiendo por ello el cristiano hacer descansar sus opciones políticas y su acción histórica en la opinión de la Iglesia o la Jerarquía, ni buscar en ellas una "garantía de autenticidad y rectitud" de sus propias posiciones. De forma definitiva, para Aldunate «la Iglesia no tiene misión de gobernar la sociedad en lo civil y temporal», siendo su papel de orientación moral en la contingencia. ${ }^{39}$

Iniciando su reflexión a partir de este punto, el subdirector de Mensaje Gerardo Claps G., SJ dedicó un artículo al problema preciso que la violencia revolucionaria representaba para el cristiano, en un momento histórico en el cual éste "se transforma en un revolucionario, esto es, en un agente activo y promotor de un cambio rápido y radical de estructuras viciadas por estructuras sanas». Desde esta posición, no debe sorprender que lo «ordinario para un cristiano sea el rechazo a la violencia», en tanto ésta iría en primer lugar contra la convivencia social, instancia en la cual el autor que citamos situaba la salvación, que se re-

\footnotetext{
39 José Aldunate, SJ. «El deber moral ante la situación revoluciona-
} ria», en RM 112, diciembre 1962, pp. 87-95. 
alizaba «en un contexto social: la gracia y el Reino poseen una dimensión social», que sería destruida por la preeminencia de la fuerza y la violencia que suponía la revolución, la que aún con finalidades legítimas, lo que hacía era "permitir a otros el empleo del mismo argumento", es decir, validar el uso de la violencia como mecanismo de imposición de un «nuevo orden», que a la larga podía conducir -como la historia de Latinoamérica lo demostraba en su opinión- a seguidillas de golpes de Estado y vulneraciones constitucionales que derivaban a fin de cuentas en «el imperio de la ley de la selva». En segundo lugar, el poder violentamente establecido recurría a la fuerza para aplacar a sus enemigos, en un proceso "abundante en recursos extraordinarios», en el cual «ningún control existe para moderar a los detentadores del poder», quienes aparecerían así dotados de una suerte de «inclinaciones despóticas», y que por ello de manera inevitable creaban un «clima de injusticias», en donde la aplicación de la violencia sobre "víctimas inocentes» era resultado esperable en un marco de «desmanes y atropellos». A fin de cuentas, la irrupción de la violencia consolidaba la división social, y «su secuela es el odio».

Dicho todo lo anterior $-y$ como ya antes la reflexión teológica había advertido- la negación absoluta de la violencia no era posible, en tanto «todos los valores que la desaconsejan son relativos y puede darse $-y$ de hecho se han dado y se da-el caso de regímenes que son agresores", aquellos que «pueden considerarse como un atropello a la dignidad humana», frente a los cuales "la revolución violenta no introduciría nuevos o mayores males y podría ser el único camino para suprimirlos». Nuevamente, el recurso al gobierno tiránico operaba como comodín de la argumentación, pero el mismo autor era consciente de que no era sostenible una discusión efectiva sobre la violencia poniéndose en la única y excepcional situación de la tiranía. El factor de previsión, de la violencia organizada que se adelantase a la agresión del gobernante o que desnudase su «radical ineficiencia» para la administración del bien común, era para Claps un campo de reflexión mucho más factible y urgente de visitar en el continente, en tanto la «perspectiva del bien común es fundamental para cualquier apreciación sobre obediencia o resistencia a los poderes públicos, a su mantención o a su reemplazo».

En tal sentido, y siguiendo muy de cerca al jesuita alemán Roger Heckel, el subdirector de Mensaje distinguía "seis condiciones de hierro» a partir de las cuales la violencia insurreccional sería aceptada por el cristiano: la degradación tiránica del gobierno o su impotencia para la consumación del bien común; el agotamiento de los medios pacíficos puestos en juego para su reemplazo; la aplicación de una suerte de "ley de proporcionalidad»: "los efectos buenos de la insurrección deben compensar los trastornos que provoca»; una segunda "ley de la eficiencia», en tanto debe contarse con una "racional esperanza de éxito». Del mismo modo, eran intolerables los «métodos intrínsecamente malos» en la ejecución de la violencia, y se consideraba ilícita la agudización de las condiciones con el fin de hacer estallar la rebelión, en tanto un actuar de esa naturaleza implicaba «usar un procedimiento intrínsecamente malo con el agravante de incurrir en la complicidad con el gobierno que busca derribar». De forma explícita para
Claps, todos los factores antes mencionados derivaban en el alto grado de responsabilidad que la política revolucionaria exigía de sus líderes, en tanto era su trabajo el impedir que luego de la revolución, quedase sembrada "la desilusión y el germen de una nueva revolución, hasta quizás el de una contrarrevolución». Por ello:

Los conductores de una revolución deben estar provistos de una enorme lucidez mental que les permita fijar claramente los objetivos y no perderlos entre el polvo y los escombros del régimen derrumbado. La meta, mientras más precisa sea, más disminuirá las posibilidades de desviación. La voluntad de construir un nuevo orden ha de ser tan firme que ningún desfallecimiento impida cumplir esta tarea. Es un verdadero peligro contentarse con destruir y no emprender nada positivo. No puede ser el odio la pasión conductora de un dirigente, menos aun de un revolucionario. Para éste la tentación es grave de creer que ha cumplido porque un régimen oprobioso ha desaparecido. ${ }^{40}$

De esa forma, en la reflexión del sacerdote jesuita los riesgos de esta responsabilidad política de la dirigencia revolucionaria obligaban a lidiar tanto con la "satisfacción» producida por la destrucción, capaz de cegar las tareas del porvenir, como contra los "extremismos» postulados por aquellos que "presentan soluciones más simples, más demagógicas y más seductoras» para la organización del nuevo orden, que en caso de seguir a éstos, lo que provocaba no era la supresión de «las injusticias, sino que las reemplaza». Por lo mismo, y como antídoto a los riesgos antes anotados, Claps reforzaba la idea de que la revolución debía ser transitoria, pues el objetivo de su irrupción estaba marcado por la recomposición de un bien común y una convivencia social que había sido fracturada antes y durante la insurrección. Era esa ruptura la que en última instancia justificaba a la misma revolución, y por ello su meta era la sutura.

Si no lo fuese, como acción perdía su justificación, y más allá de ello, «sus normas son provisorias, como corresponde a un estado de lucha, asentarlas como definitivas sería un abuso", cayéndose por ello al prolongar la vigencia del estado de excepción revolucionario en "la tiranía y en un odioso paternalismo». Este factor se explicaba por lo general tanto por «la comodidad de gobernar sin oposición ni controles», como por la «pretensión de algunos líderes de creerse ellos mismos necesarios e insustituibles». En el fondo ambas modalidades de excepción lo que demostraban a juicio del jesuita era la desconfianza en «la madurez política de las masas y su capacidad para comprender el problema y sus soluciones». Finalmente, eran esos mismos dirigentes los que debían cautelar el desarrollo de la revolución en los marcos de la justicia en sus procedimientos, en tanto «es un desdoblamiento y una traición a los ideales profundos de una revolución justa el propender a una meta más humana, atropellando los derechos humanos por el camino», por el hecho de que ello significaría «dar a la revolución un carácter absoluto y subordinar al hombre a ella», factor crítico que aparecerá reiteradamente en la tematización católica de la revolución, puesto que era una de las vías a partir de las cuales el concepto de Revolución

40 Claps G., «El cristiano frente a la revolución violenta», en RM 112, diciembre 1962, pp. 138-145. 
fue temporalizado por los cristianos que lo incorporaron a su matriz de pensamiento trascendente. En otras palabras, el carácter de fin establecido para la revolución le permitía obviar la naturaleza de los medios para su consecución, y ese era el límite de la violencia que ningún cristiano podía estar dispuesto a sobrepasar. Para Claps, «nunca será lícito recurrir a las torturas o a los actos de terrorismo. Nunca será legítimo calumniar al adversario o amedrentarlo con castigos inferidos a inocentes.» El camino de resistencia a estos riesgos era -y en una clave de confirmación de la audiencia católica de estas reflexiones- un "verdadero humanismo revolucionario», que hiciera a los líderes «luchar por el hombre y no por ideales subalternos», tan graficados en la «etapa heroica» de la revolución, pero necesariamente sujetos a la recomposición del bien común, dentro del cual evidentemente se encontraba también aquel que en la lucha revolucionaria había sido calificado de enemigo. ${ }^{41}$

De esa forma, la reflexión en torno al componente de violencia de la acción política revolucionaria desarrollado por el sacerdote que venimos citando evidenciaba, junto con los tópicos preventivos a los que se ha hecho alusión, la inminencia del involucramiento directo de algunos cristianos del continente y Chile en movimientos insurreccionales, y como permite interpretarlo el foco puesto en gran parte del texto en las responsabilidades del liderazgo, en una situación directiva antes que solo de acompañamiento pasivo u homogeneidad de masa. Ello le aportaba complejidad al proceso, en tanto en la inminencia de la revolución el "cristiano ve que no está solo", sino que flanqueado por el marxismo, que a juicio de Claps "quiere para sí el monopolio de la revolución y asegurar, por lo menos, su iniciativa. Por táctica, busca colaboradores pasajeros, que luego son arrojados por la borda». Es decir, la vecindad entre cristianos y marxistas era inevitable en el plano de la revolución justa, pero la colaboración práctica seguía cargada de riesgos. Para no «ser arrojados por la borda», debían los cristianos apropiarse de la revolución a través del conocimiento y la denuncia de la miseria y el sufrimiento que la antecedían, así como comprometerse lealmente con el cambio de las estructuras inevitable, y así impedir su deriva contraria al bien común. ${ }^{42}$

Dicho lo anterior, sin embargo, la tematización cristiana de Revolución seguía necesariamente encadenada a la praxis marxista de la misma. Por ello, y de modo coherente, el último de los artículos del número de diciembre de Mensaje que ha concentrado nuestra atención hasta aquí hacía referencia a ésta, bajo el inequívoco título de "El desafío marxista». En este artículo el arquitecto democratacristiano uruguayo Juan Pablo Terra advertía en primer lugar que el marxismo era «una fuerza lanzada a transformar al continente creando una sociedad más justa, y superando a las otras fuerzas que pretenden construir su futuro». Como tal, el marxismo representaba para este autor una doble complejidad ante el cristianismo: se oponía sistemática y "científicamente» a buena parte de sus creencias fundamentales; pero al mismo tiempo, arraigaba «profundamente en la entraña misma de ciertas verdades cristianas». Por eso, si los cristianos querían entrar al campo de la revolución debían contar, en primer lugar "con el deseo intenso de transformación hacia la justicia», poniendo este fin como el orden del día superior, única forma capaz de equilibrar la energía revolucionaria detectada en el marxismo, y al mismo tiempo, la convicción indispensable que distinguiría a los cristianos de aquellos «reaccionarios y conservadores» que se oponían a los cambios.

Despejada esa definición, el autor organizaba su reflexión a partir de las hipotéticas situaciones revolucionarias posibles de verificarse en América Latina: aquella protagonizada desde un inicio por cristianos; la que en desarrollo era posible dotar de alguna orientación cristiana; una que ha sido ya controlada por el marxismo y por lo tanto debe ser combatida por los cristianos y finalmente aquella en la que incluso esa posibilidad de resistencia cristiana ha desaparecido. En este caso la que más interesa revisar es la primera, presentada por el autor como la «revolución propia», es decir, «aquella de un partido constituido en torno a un programa de inspiración propia»; o al menos por uno «cuyo contenido fuese conciliable o concordante con la concepción cristiana del hombre y de la vida y en el cual cristianos y no cristianos militasen juntos». Para efectuar este liderazgo cristiano de la revolución -y no dejar que ésta "derive» hacia el marxismo- Terra recomendaba en primer lugar la creación «de un estilo político que, capacitándole la conducción de masas sea leal a los valores de su propia concepción». Así, el diseño propuesto obligaba a la constitución de al menos «un movimiento universitario, una fuerza obrera, una organización campesina y un partido político» que articulasen la acción revolucionaria cristiana, en un indisimulado giño al tipo de asociaciones que componían por aquel entonces el corazón de la acción política y social cristiana en Chile. Una clave más que agregaba Terra era la existencia de unas Fuerzas Armadas animadas por «un sentido inquebrantable del respeto al juego institucional, o una comprensión suficientemente lúcida de la naturaleza del proceso revolucionario, como para prescindir al menos de interferirlo». De esa forma, el protagonismo cristiano en la revolución se hacía factible a partir de tres ejes de coincidencia: la fortaleza de un ánimo cristiano revolucionario auténtico y leal con los principios evangélicos; una plataforma de acción política de masas variada y de arraigo tanto elitista como popular; la concurrencia de un escenario institucional en el cual las FF. AA. actuarían de forma prescindente. A juicio del autor «la revolución propia es más probable en Chile que en cualquier otro país del continente. Y también la revolución marxista respetuosa del pluralismo orientable». ${ }^{43}$

\section{DEBATES Y PRECISIONES: LAS REACCIONES A LA CONCEPTUALIZA- CIÓN DE MENSAJE}

Las reacciones que el número de Mensaje dedicado a la revolución suscitó fueron muchas y muy contundentes, en términos tanto de evidenciar la centralidad de este debate conceptual para la articulación política católica, como la profundidad de las diferencias que la controversia sacaba a la luz. Así, en su número de fin de año Política y Espíritu -publicación del Partido Demócrata Cristianodedicó un artículo a reseñar las críticas que desde el

\footnotetext{
41 Ídem.

42 Ídem.
}

43 Juan Pablo Terra, «El desafío marxista», en RM 112, diciembre 1962, pp. 146-152. 
bando conservador se habían difundido en relación con los contenidos presentados por la publicación jesuita. Se anotaban así tanto declaraciones radiales como opiniones publicadas en El Diario Ilustrado (representante del catolicismo más conservador), que en lo fundamental aludían a una apología de la revolución violenta por parte de Mensaje, que derivaba necesariamente en la colaboración con lo que definían como el totalitarismo comunista. Junto a ello, la propia dinámica de transformación social que la revolución suponía fue puesta en cuestión -aludiéndose con ello a un factor de fondo en este debate en torno a la naturaleza del cambio histórico y sus posibilidades de orientación cristiana-, en tanto para el periódico conservador era «reprochable una revolución que significa un cambio integral de estructuras sociales. Este cambio 'a partir de cero' es una utopía peligrosa», y además, estaría en oposición a la doctrina central de la Iglesia católica dirigida hacia un "método evolutivo, reformista», que se veía obstaculizado por la misma retórica de la revolución, en tanto ésta introducía «un pesimismo esencial entre los hombres dedicados a la tarea de mejorar la realidad" a la vez que alentaba «en las masas actitudes de pura rebeldía». De esa forma, los conservadores convocados al debate -el diputado Jorge Hubner y el destacado dirigente de la Acción Católica Fernán Luis Concha- alertaban tanto por el riesgo de introducir el lenguaje revolucionario al interior de la reflexión católica, como la amenaza de que dicha inserción derivase en la colaboración con el comunismo.

La respuesta a estos argumentos que la sensibilidad democratacristiana elaboró se ubicó en estricta consonancia con la reflexión jesuita, en tanto se despejaba desde un primer momento la defensa de la violencia revolucionaria acusada por los conservadores, insistiéndose en el carácter reformista de la política cristiana, que debía ser cuestionada solo cuando era insuficiente «para responder a la gravedad del problema». Por ello, la reforma dinámica y verdadera era el cambio social «con la oportunidad, la profundidad y la amplitud que las necesidades exigen». Y esa era la hora del continente, en tanto "el cambio sustancial y universal de las estructuras en América Latina aparece como un hecho, una necesidad histórica y que, por eso mismo, hay que llevarlo a cabo dentro de la filosofía cristiana -icapaz de asumir esta tarea!».44 De ese modo, y fuera de la tradicional disputa entre conservadores y democratacristianos por la «recta interpretación» de una política católica, lo que el debate en torno a Revolución dejaba de manifiesto era la voluntad de cambio que unos y otros asumían, esa directiva que ya Fichter había tematizado al hablar de progresistas o tradicionalistas al interior del universo católico chileno.

En el caso de los comunistas, su opinión en torno al contenido de la revista Mensaje se dirigió hacia la vinculación de la conceptualización católica con las definiciones del Partido Demócrata Cristiano y sus inspiraciones, particularmente la Alianza para el Progreso promovida por los Estados Unidos en el mismo periodo como alternativa a transformaciones asimilables a las acontecidas en la Cuba revolucionaria. Así, a juicio del diputado comunista Orlando Millas, los artículos de la publicación jesuita sintetizaban «el

44 "Un 'Mensaje' revolucionario», en PyE 277, diciembre 1962enero 1963 , pp. 42-44. pensamiento democratacristiano». El objetivo y alcances de este ideario de inspiración cristiana eran claros para Millas:

La introducción al lenguaje democratacristiano del término revolución la vincula de hecho a los alcances de esa palabra en el vocabulario del propio Kennedy. Sostiene que, para que no quepan dudas, que «al condicionar su ayuda a las reformas (agraria, tributaria, educacional, administrativa, etc.), la Alianza para el Progreso ha reconocido claramente la ineludible necesidad de la revolución en América Latina». O sea, se trata de una «revolución contrarrevolucionaria», que han salido a predicar apresuradamente Kennedy y Vekemans. ${ }^{45}$

De forma global, la evaluación que Millas hacía de las contribuciones de los artículos publicados por Mensaje era de interés, pero a su juicio éstos se hallaban definidos por un «reformismo burgués tímido, inconsecuente y que en verdad no enfrenta los grandes problemas de nuestro tiempo», y que por ello aun cuando tomase el «el gran rótulo de la 'revolución', lo que hacía era negarla de inmediato», en tanto el marco que daba cabida a todas las reflexiones editadas por la revista de la Compañía de Jesús era definido como «reaccionario». ${ }^{46}$

Las reacciones a la publicación jesuita no se detuvieron, y su expresión varió en relación a los agentes que opinaran y el lugar desde dónde lo hicieran. Así, por ejemplo, el semanario del Arzobispado de Santiago en su sección de cartas recibió opiniones que consideraban no solo a Mensaje, sino también a La Voz y sus comentarios como responsables de "una grave desorientación espiritual entre los católicos», que se verificaba en primer lugar en su «ataque sistemático a la gente con dinero, a la que se insulta y presenta como réprobos de la sociedad", olvidando que "son las personas de fortuna las que mantienen con sus limosnas las numerosas obras de caridad privada y las que sostienen a la Iglesia con sus donaciones constantes y sus legados", además de ser éstas mismas personas acomodadas quienes "frecuentan la Iglesia, reciben los sacramentos y defienden a los sacerdotes de los ataques de ateos y marxistas». Anexo a ello, sin embargo, para el airado redactor "las referencias a la 'revolución en marcha' tan difundidos», lo que hacían era "producir una psicosis revolucionaria que puede causar una revolución, a cuyo término no veremos otra cosa que escombros, ruina y muerte de la Iglesia y los católicos».47

Este tipo de juicios buscaron ser matizados desde el mismo semanario, al momento en que José Gorbea -seudónimo del laico de largo compromiso católico Javier Lagarrigue A.- realizó una distinción entre el carácter histórico y táctico del concepto, y su plano estratégico. Así, a su juicio la revolución históricamente estaba vinculada a

45 Millas, O. «El pensamiento de Vekemans», artículo publicado en El Siglo el 30 de octubre de 1963, recogido en Millas 1964: 89-90. Agradezco al historiador Alfredo Riquelme S. la referencia de este texto. Se refiere al jesuita belga Roger Vekemans, residente en Chile durante el periodo que analizamos y responsable de la articulación de centros de estudio social y político vinculados a la Iglesia católica como ILADES y el Centro Bellarmino. Al respecto, ver Beigel 2011.

46 Millas, O. «Enfoques reaccionarios», artículo publicado en El Siglo el 13 de noviembre de 1963, recogido en Millas 1964: 105-107.

47 Ossandón, R., «El dinero y la verdad», en LV, 17 de febrero 1963, p. 2. La respuesta del semanario fue lacónica: «No atacamos a la gente con dinero ni incitamos al odio y la revolución violenta. Tratamos de abrir los ojos a las personas a quienes el dinero no les deja ver la realidad». 
la conceptualización marxista, que suponía la comprensión del cambio social y cultural como «una lucha por destruir un régimen y cambiarlo totalmente por otro». Por ello «la política misma se concibe como la construcción de fuerzas capaces de hacer la revolución y el diseño de tácticas y métodos para realizarla», todo lo cual redundaba necesariamente en que «la política deja de ser un debate pacífico en la convivencia y se transforma en la preparación de un choque, planteándose la crisis del sistema democrático». Ese factor destructivo inherente a la conceptualización marxista de la revolución era lo que hacía que, a juicio de Gorbea, para el cristiano fuera imposible «coincidir ni doctrinaria, ni políticamente» con tal revolución, "porque no hay en ella lugar para el concepto de libertad, que es esencial a nuestra afirmación del valor de la persona», a lo que se sumaba que la revolución marxista, proyectada sobre la realidad «contempla la violencia como un elemento propio y natural», y que por ello motiva la preparación y organización de la violencia «moral y materialmente».

Hecha esa suma de distinciones, Gorbea afrontó la tarea de elaborar una conceptualización "positiva» de la revolución, una semantización que pondrá el acento en lo estratégico antes que en lo táctico, un proceso de apropiación conceptual inspirado -de acuerdo a sus propias palabras- en la Carta Pastoral «El deber social y político en la hora presente» publicada en septiembre de 1962 por el Episcopado chileno, en tanto la posibilidad de una revolución cristiana debía iniciarse en «un juicio moral sobre la realidad» que diera paso a «una orientación o finalidad, también moral», que la Carta Pastoral había definido tanto por sus críticas al orden capitalista, como por su rechazo al anticomunismo negativo al mismo tiempo que al paternalismo caritativo de viejo cuño, ambas herramientas insuficientes para abordar los cambios estructurales que la sociedad chilena demandaba. Es decir, la crítica políticomoral contenida en el documento episcopal representaba para Gorbea «un concepto moral anterior y superior a la teoría y a la acción revolucionaria», y en tanto superación, permitía la elaboración de una versión «de revolución plenamente legítima, eventualmente aconsejable, y aún necesaria», en tanto el alcance de la revolución estaba ajustado al grado de sustituir o reemplazar aquellos aspectos «injustos» de un orden económico-social determinado, injustos en tanto violatorios de «los derechos de la persona humana, y por ende, la moral cristiana».

En el fondo, esta definición desesencializaba a la revolución, en tanto la delimitaba a aspectos específicos de la vida social y le restaba el carácter inevitable a partir del cual era concebida por la interpretación marxista. Así, a fin de cuentas, para el redactor, los Obispos en la Carta Pastoral habían establecido un juicio conforme al cual eran posibles tanto una doctrina revolucionaria y una política revolucionaria que representasen «no la crisis de la Democracia, sino la superación de esa crisis; cuya fuerza sea la decisión ilustrada de una mayoría popular actuando en plena libertad, con los instrumentos del régimen de derecho, de la legalidad». ${ }^{48}$ De forma nítida, la posibilidad de una «Revolución en Libertad» se avizoraba en el pensamiento

48 Gorbea, J. «Revolución ¿Sí o no?», en LV, 24 de febrero 1963, p. 16. católico, prefigurándose así a inicios de 1963 una consigna que se haría gobierno a partir del año siguiente.

En las mismas páginas de Mensaje las réplicas a los contenidos del número en cuestión no dejaron de sucederse. En tono polémico, por ejemplo, un lector advertía la contradicción entre la publicación jesuita -«Mensaje en rebeldía»-y las orientaciones con respecto a la negatividad de la revolución expuestas en los documentos pontificios. A su juicio, la «soberbia» de los redactores de la revista les impedía percibir que las deficiencias del orden vigente capitalista se debían a problemas como «la embriaguez, el robo, la irresponsabilidad, el trabajo lento, etc.». Tras ello, preguntaba a los sacerdotes:

¿No han tenido nunca ustedes un obrero a su servicio? ¿Saben cuánto se roba en las industrias, en las construcciones, en los fundos, aparte del trabajo a media velocidad? Las causas de la pobreza en Chile son, en un ochenta por ciento, de orden moral. Para el criterio marxista de Mensaje son exclusivamente de orden estructural y económico, y no tienen otra solución que la revolución. ${ }^{49}$

Para argumentar su crítica, el lector hacía referencia a un largo artículo publicado meses antes por el profesor de la Universidad Católica de Valparaíso Jorge Siles S. -de nacionalidad boliviana y él mismo "víctima» de la revolución de 1952 en su país- en la revista Finis Terrae, del Departamento de Extensión Cultural de la Pontificia Universidad Católica de Chile y plataforma recurrente de la reflexión católica tradicional. En este artículo, Siles analizaba a la revolución contemporánea como producto de un doble y paradójico movimiento, consistente por un lado en «la negación de la historia, esto es, el propósito de hacer borrón y cuenta nueva con el pasado a fin de empezar una vida nueva, previa la liquidación radical de ese pasado». Como oposición a esto, pero actuando en la misma dirección, se encontraba «una divinización o glorificación de la historia, cuyos resultados u objetivaciones se reputan como momentos necesarios de un proceso que condiciona e imprime un sentido a la vida humana». La implicación comprensiva de este doble movimiento era para el autor el reconocimiento de que la conceptualización al uso de revolución -en su variante racionalista e historicista antes reseñado- estaba ineludiblemente unida a la matriz del cristianismo, en tanto:

Sería tarea vana intentar comprender el significado profundo de la Revolución fuera del marco histórico delimitado por el cristianismo, frente al cual aquella representa un movimiento de des-sacralización del mundo, a la vez que una filosofía de la historia que tiende a colocar al hombre en lugar de Dios mediante el doble culto de la Razón y de la Historia. ${ }^{50}$

Es decir, para Siles la conceptualización contemporánea de la Revolución producía el efecto de secularización invertida postulado por Blumenberg, en tanto no era un teologema temporalizado, sino un concepto secular elevado a la trascendencia. ${ }^{51}$ En el plano de lo inmediato, Siles reconocía

\footnotetext{
49 «Mensaje en rebeldía», en RM 117, marzo-abril 1963, p. 71.

50 Siles J. 1962. "Las dos fuentes de la revolución contemporánea», Finis Terrae 35: 3-5. Agradezco al historiador Claudio Rolle C. la indicación del valor de esta fuente para mi investigación.

51 Blumenberg 2008: 13-120.
} 
que el objetivo de su reflexión era «oponerse a la corriente demagógica que hoy invade nuestros países», en los cuales «todos los grupos y las personas se diría que rivalizan en un revolucionarismo irresponsable». ${ }^{52}$ Más aún, el boliviano escribía a partir de su propia experiencia de exilio a partir de 1952, y advertía que "ni en cuanto a las causas que determinaron tal estallido ni en cuanto a sus consecuencias», parecía existir en quienes «debieran estar prevenidos para evitar la contaminación, ninguna voluntad ni de enmienda en la conducta ni de previsión profiláctica ante la posibilidad de conocer por propia experiencia los males que otros ya sufrieron». A su juicio, ello se vivía en lo contingente, en tanto

una corroboración patente de tal incapacidad puede apreciarse en el hecho de que, teniendo presente el recentísimo ejemplo del fracaso revolucionario boliviano, los políticos chilenos de derecha no han hecho nada por utilizar el riquísimo caudal de propaganda que el caso de Bolivia les podría suministrar. Pues si la extrema izquierda chilena esgrime hoy el ideal revolucionario, a un tiempo como panacea de los males existentes y como amenaza para intimidar a sus adversarios, ¿no hay quien haga ver a esos extremistas que la Revolución prometida ya ha sido en la vecina Bolivia una experiencia real, una experiencia de descalabro y desintegración? ${ }^{53}$

Sordos ante la experiencia ajena o pasada, Siles cuestionaba que los países americanos no se protegiesen del avance de la revolución, y que se considerase a ésta como «la palabra talismán, la palabra que parece concitar todos los fervores de la juventud, el santo y seña de los nuevos tiempos». Más allá de ello, el autor hacía referencia a aquellos cristianos que adoptaban a la revolución para denominar «un movimiento orientado a la reforma de las costumbres y de los sistemas educativos, comportando por tanto cambios que no exigirán la intervención de la violencia ni las represiones terroristas», en tanto no percibían con claridad que «el signo verdadero de la Revolución moderna, que brota de la Revolución Francesa y se identifica en nuestros días con la Revolución Marxista, es fundamentalmente anticristiano», por lo que "representa una ingenuidad imperdonable pretender imprimir un carácter cristiano a lo que obedece a la finalidad expresa de combatir y perseguir al cristianismo». ${ }^{54}$ Esta ceguera, además, provocaba que se señalase a las causas de la Revolución como inscritas en la injusticia y la privación, cuando su análisis histórico demostraba -siempre a juicio de Siles- que «las causas verdaderas de la Revolución son la utopía, las ideologías abstractas, la racionalización de la política, la pérdida de la conciencia histórica», muy en línea con las bases del pensamiento conservador que él mismo reseñaba en las figuras de E. Burke y J. Donoso Cortés. ${ }^{55}$

Tras ello, las referencias al Terror jacobino y las desgracias de la isla de Corciras citadas por Tucídides permitían a Siles epitomizar: «la revolución es un mal» ${ }^{56}$, y por ello la «revolución cristiana» era un desatino. Junto a ello, lo que el ver-

52 Siles, J. 1962: 5.

53 Ibídem: 7-8.

54 Ibídem: 9-11.

55 Ibídem: 16. La vinculación entre esta característica del pensamiento conservador, el uso de la Historia y la conceptualización antiteórica de la experiencia es analizada por Jay 2009.

56 Siles, J. 1962: 31. dadero católico debía hacer ante el cambio histórico era la reivindicación «del Orden, de la Norma, de la Tradición» ${ }^{57}$, o dicho de otro modo, hacer «no la revolución contraria, sino lo contrario de una revolución». ${ }^{58}$ ¿Qué significaba aquello?, pues la restitución de la continuidad de la historia, en tanto «lo quiera o no lo quiera, el hombre es un ser histórico, un heredero; uno de los derechos primarios de la vida humana en sociedad es, por lo tanto, el de la continuidad histórica».59 La articulación de la reforma, del cambio y la acción social en ese marco estaría definida así dentro de "los límites que ningún ser humano puede transgredir, sean los que sean los fines que su actividad persigue», en tanto el reconocimiento de esto permitía para el autor «trazar el marco de la actuación social propuesta por el cristianismo dentro de la esfera de lo posible, lejos de los utopismos que propicia la revolución de nuestro tiempo». ${ }^{60} \mathrm{Al}$ final, en palabras de Siles, «en la hora presente no le queda a Hispanoamérica, sin duda, sino la posibilidad de escoger entre un orden social cristiano y la sangrienta aventura de una Revolución social». ${ }^{61}$

De esa forma, lo que el lector de la revista jesuita hacía al momento de referenciar al artículo filosófico que hemos reseñado era confrontar directamente al cristianismo con la idea de revolución, indicando que la genealogía y uso de ésta eran en lo fundamental anti-católicos, como una herramienta secular burda y sangrientamente sacralizada una y otra vez. Como era de esperarse, la redacción de Mensaje defendió sus propias opciones ante ésta y otras críticas que sabrían habrían de venir, y sagazmente iniciaba la editorial del número siguiente a la polémica publicación reconociendo la inevitabilidad del debate surgido, en tanto "frente a problemas complejos y 'vitales', de los que no somos solamente espectadores sino protagonistas, era difícil contar con un consenso unánime». Pero, inmediatamente anotaban, «la polémica nos desilusionó», en tanto "todo se redujo prácticamente a discutir sobre el uso de la palabra revolución», y no se mostraban dispuestos a "continuar con una querella de diccionarios», que opusiera revolución a reforma, a restauración o consagración. Lo que les importaba era que se había concentrado la reflexión de Mensaje en el carácter cristiano de la revolución, aunque en esa línea muchas de las críticas recibidas les hacían pensar que si los críticos habían leído efectivamente el número en cuestión «no han entendido nada».

Obligados por ello a clarificar su propia acepción de revolución, la redacción resolverá subrayar el contenido restaurador de la revolución cristiana, en términos de que "si lo que habitualmente se llama orden social, político, jurídico y económico es, en lenguaje cristiano, un 'desorden', tenemos la obligación de luchar contra ese pseudo-orden y 'restaurar' el orden verdadero, el de Cristo». Pues bien, "a esa innegable y necesaria restauración hemos dado el nombre de revolución cristiana». Las bases evangélicas de esta conceptualización restitutiva se enumeraban en lo fundamental desde las perícopas de la disposición cristiana a la ayuda a los más pobres, la trascendentalidad del amor como último horizonte y la desconfianza en la autenticidad

\footnotetext{
57 Ibídem: 19.

58 Ibídem: 31.

59 Ibídem: 37.

60 Ibídem: 39.

61 Ibídem: 42.
} 
de la fe de parte de aquellos aferrados a los bienes materiales y satisfechos con la sola caridad, dirigiéndole a estos últimos una interrogación:

¿Por qué este temor reverencial a cambiar estructuras que hacen posible que millones y millones de hombres no posean más que su miseria y su desesperación? No se trata de echar todo por la borda y destruir por destruir. Evidentemente debemos conservar todo lo que merezca ser conservado, pero ¿por qué ese instintivo horror a la frase "cambio de estructuras»? ¿Están nuestras leyes inspiradas en el Evangelio? ¿Es la empresa moderna una acabada muestra de comunidad cristiana? ¿Responde el sistema que ha imperado en nuestros campos a lo que dice Cristo a través de su Iglesia?62

Por ello, ante la tensión entre conservación y reforma, el llamado a la acción por parte del medio jesuita era explicito, una acción que reivindicaba una alineación de los agentes católicos, una coordinación fundada en la urgencia de la praxis: "lo importante es que nuestros ojos se abran no por el temor sino por el amor. No es la hora de la discusión, sino de la acción. Debemos deponer rencillas particulares y banderismos infantiles y unirnos en la gran cruzada cristiana», iniciativa la cual significaba que «manteniendo lo que hay que mantener debemos tener el coraje de reformar lo mucho que hay que reformar, y esto sin tardanza». ¿Qué dimensión ocupaba, en ese esquema, la tradición, la historia, aquello que debía ser conservado? Claramente, no era lo más importante, pues el régimen de historicidad que la revolución promovía se arrojaba al futuro, y la consecución del orden cristiano -una vez más- estaba allí instalada. ${ }^{63}$ Para Mensaje, «debemos respetar el pasado, pero no encerrarnos en él. El pasado solo vive y tienen sentido cuando se asoma al presente y marca rutas para el futuro. Transformar el pasado en refugio es condenarnos a ser estatuas de sal». ${ }^{64}$ Así, el debate semántico era llevado a la prueba de fuego de la contingencia y la acción, desde lo estrictamente nocional se derivaba a la eficacia evangélica, del reposo de la contemplación del pasado y su desenvolvimiento, se urgía a la transformación, a la intervención en el mundo y sus injusticias.

\section{EL PROBLEMA DE LA EFICACIA: LA CONCEPTUALIZACIÓN CRISTIANA} DE LA REVOLUCIÓN ANTE LA CONTINGENCIA HISTÓRICA

Ese tipo de lectura -aquellos que comprendieron, de acuerdo al criterio de Mensaje- la Confederación Latinoamericana de Sindicatos Cristianos hacía suya al declarar

\footnotetext{
62 «iRestauración... pero de verdad!», en RM 117, marzo-abril 1963, pp. 79-81.

63 El análisis de los regímenes de historicidad como factores de disposición temporal -futuro, presente, pasado- para una determinada sociedad se discute en Delacroix, Dosse y García (editores) 2010.

64 Ídem. Un par de números más adelante, un tono crítico sobre la acepción jesuita de la necesidad de la revolución se repetía en una carta del director del Departamento de Medicina de la Pontificia Universidad Católica de Chile, el Dr. Ramón Ortúzar E., a juicio de quien -y haciendo específica referencia a un artículo del belga Roger Vekemans- la demanda de una ruptura revolucionaria implicaba desconocer la importancia que para el país representaban factores de estabilidad y progreso que no debían ser modificados de forma abrupta, como el sistema escolar, la institucionalidad política y las reformas que ya estaban en marcha bajo el gobierno de Jorge Alessandri. «En desacuerdo», en RM 119, junio 1963 , pp. 207 y $279-280$.
}

que "América Latina está bajo el signo de la Revolución, necesaria, inevitable e impostergable», proclamando al sindicalismo cristiano como «el fermento y la vanguardia de la Revolución.» ¿De qué naturaleza era esta revolución? Evidentemente, no era comunista, en tanto «no es el comunismo la revolución que desean los trabajadores de América, porque el comunismo no es auténticamente revolucionario, sino que ha sido, es y será, el más déspota de los capitalismos de Estado». La revolución cristiana tenía en consideración "al hombre, al individuo, a la familia», en tanto era «la revolución que da el pan junto con la libertad; que no sofoca la libertad para dar un poco de pan, como lo hace el comunismo, ni quita el pan para dar una ilusión de libertad como hace el capitalismo». En este contexto, la revolución cristiana se proclamaba como programa de transformación centrado en reformas de naturaleza acotada, expresadas en las siguientes consignas:

Que cada hombre de América Latina tenga la posibilidad cierta de trabajo.

Que cada trabajador tenga una remuneración suficiente para vivir con dignidad y mantener dignamente a su familia. digna.

Que cada trabajador sea dueño de una casa-habitación

Que cada trabajador, por intermedio de sus representantes, elegidos libre y democráticamente, tenga parte en la dirección de la economía.

Que cada campesino sea propietario de la tierra suficiente, que le permita vivir dignamente a él y a su familia.

Que sea eliminada o se le cierre el paso a todo tipo de dictadura, sea esta comunista, militar o fascista.

Afirmamos en su plenitud la Carta de los Derechos Humanos de las Naciones Unidas y exigimos su cumplimiento estricto.

Nuestra revolución no debe ser asentada ni impuesta por el paredón o la sangre de hermanos, sino por la unión decidida y constructiva de las fuerzas democráticas de América. ${ }^{65}$

Así caracterizada, la revolución cristiana se distanciaba por igual del comunismo y el capitalismo, poniendo acento en una noción de bienestar individual organizada a partir del trabajo y la propiedad, así como en una versión convencional de los roles familiares. Una revolución de trabajadores responsables, campesinos esforzados y madres hogareñas, sin enfrentamiento violento, sin paredón y respetuosa de los Derechos Humanos. Una revolución centrada en la reforma.

El mismo tópico será debatido a la luz de la encíclica de Juan XXIII Pacem in Terris, que con una intención de apertura a la colaboración en pos de la paz entre católicos y no católicos, podía ser interpretada como legitimadora de una revolución, entendida como una fase necesaria para el cambio de estructuras que beneficiara a los más desfavorecidos. Así, en las páginas de $L a$ Voz se verificó la contraposición entre un lector y la redacción del semanario sobre el particular. Para el primero, el Pontífice era claro al expresar que "los católicos no deben usar el término revolución cuando desean cambios en las estructuras sociales, ya que la revolución es contrapuesta a la paz», y que estos cambios debían ser alcanzados a través de "un crecimiento por etapas sucesivas». Quien no entendiera eso

65 «En el día del trabajo un mensaje de esperanza», en LV, 5 de mayo 1963, p. 20. 
y usase el concepto de Revolución utilizaba «las palabras del Pontífice para justificar sus errores», cayendo con ello en el «orgullo y la soberbia, algo inconcebible en un periódico católico como La Voz».

Como respuesta a tales argumentos, y mediando la consulta a un anónimo teólogo, la editorial del semanario del Arzobispado de Santiago sostenía que «si hay grupos cristianos que aspiran a una enmienda y reforma de estructuras, y a eso le llaman revolución, con criterio de cambio acelerado, no contravienen en nada las nociones dictadas por el Papa», destacando a su vez que la oposición a una revolución violenta era indiscutible tanto en la encíclica que se citaba, como en el mensaje cristiano en general. Dicho lo anterior, la editorial concluía que lo importante era el involucramiento cristiano en la mejora de las condiciones de vida de los más desfavorecidos, posición que exigía «sacrificios indispensables». Si se estaba «dispuesto a hacer estos sacrificios, a cambiar la íntegra y compleja estructura de la sociedad para hacerla justa y cristiana, daría lo mismo que le llamaran evolución, revolución o de cualquier otro modo». ${ }^{66}$ De forma simplista, la querella entre reforma y revolución se buscaba apagar con una sinonimia que solo confundía.

Un paso hacia la clarificación semántica la aportó en este debate José Gorbea, asiduo redactor del semanario católico, que planteó la posibilidad así de una «revolución evolutiva» como de una "evolución revolucionaria». El juego de palabras poseía un sentido profundo: la naturaleza del poder y las vías legítimas para su control. Citando en primer lugar al Lenin del «Izquierdismo, enfermedad infantil del comunismo», Gorbea argumentaba en torno a la peligrosidad que el ruso observaba tanto en contrarrevolucionarios como en izquierdistas, en términos de hacer de las acciones "revolucionarias» un fin en sí mismas y no un medio de transformación. Si bien el debate entre los católicos no podía ser asimilado al sostenido por el bolchevique, para el político cristiano la revolución podía ser evolutiva si permitía -nunca a través de la violencia, por supuesto- que «un nuevo régimen de justicia y libertad crezca como una semilla». Sin embargo, más factible aparecía la figura de la "evolución revolucionaria», que suponía no la toma revolucionaria del poder -disruptiva, violenta-, sino «la construcción dentro de la comunidad social, de los criterios de justicia y libertad; de los métodos de eficiencia práctica, y de las instituciones adecuadas de realizar la justicia y la libertad». Siguiendo el modelo de la institucionalización imperial romana, «llegar al poder no es, para el cristiano el momento de 'empezar a hacer', sino culminar, con los medios del poder lo que estaba haciendo antes: la creación de una nueva orientación para toda la comunidad social», utilizando para ello no las tácticas «maquiavélicas» del comunismo, sino «el

66 "Querella de diccionario. Los papas y la revolución», en LV, 5 de mayo 1963, p. 13. Es interesante anotar aquí que la recepción de la encíclica por parte del partido Comunista de Chile fue en gran medida positiva, en tanto se reconocía en un informe ante el Pleno del Comité Central que "la reciente encíclica Pacem in Terris promueve una colaboración de católicos y no católicos, sin exclusiones, a favor de la causa más noble y esencial, cual es la defensa de la paz. Deja abierta, también, esta puerta la colaboración para otros objetivos de alta trascendencia humana, entre los cuales puede y debe figurar, en nuestro caso, remover los obstáculos para una vigorosa renovación democrática.» Citado en «E Diputado Orlando Millas, un Pontífice contradictorio», en LV, 16 de junio 1963, p. 6. recurso al pueblo, a la comunidad, para que ella constituya su poder», realizándose así el ascenso de "una conciencia general mayoritaria, antes formada, de la cual se puede decir que el poder llega a ella». En ese momento «la evolución se hace revolucionaria, no solo porque se hace rápida, radical y profunda sino porque es como el florecimiento y la fructificación de una realidad construida antes». ${ }^{67}$

En el fondo, lo que se ponía en cuestión en la argumentación anterior era la comprensión táctica de la Revolución, en tanto procedimiento de asalto al poder por parte de una minoría o conclusión de la voluntad de una mayoría movilizada en torno a ciertas demandas de transformación. De forma muy lúcida, se ponía en el centro de ese debate táctico la noción de poder constituyente que, siguiendo una lógica arendtiana, se articulaba o desde arriba o desde abajo, operando la revolución cristiana caracterizada por Gorbea como un factor constituyente desde abajo, y por ello, eximida del recurso al "maquiavelismo» y la violencia inherentes históricamente a la concepción marxista de la revolución.

De ese modo, la conceptualización cristiana de la revolución, en distintos niveles de expresión y articulación política, era dotada en lo fundamental de la cualidad del consenso, es decir, de ser un proceso generado por el acuerdo ma-yoritario en torno a la necesidad de la transformación, o como lo expresó un lector del semanario del Arzobispado -haciendo suya la expresión de Charles Péguy- «la verdadera revolución será espiritual o no será», reivindicando además que «la Revolución es una institución cristiana por excelencia, y son en verdad los marxistas los que la han desfigurado». Era cristiana «porque no puede haber ni hubo cosas más revolucionarias que la encarnación de Dios y la transformación radical del mundo por doce pescadores reputados de ignorantes y locos». ${ }^{68}$ En la misma senda, y con un calado trascendental mayor, se expresaba el teólogo belga de larga residencia en Chile José Comblin, quien advertía sobre la necesidad de "revelar el destino cristiano de la humanidad", y no solo "bautizar» los mitos de la realidad moderna, como eran «la Democracia, el Progreso, la Revolución, el Socialismo", como se hacía al hablar de una "democracia cristiana, progreso cristiano, revolución cristiana, socialismo cristiano». En el fondo, si la acción de los católicos -la misión- «no enfrenta para superarlos los grandes mitos modernos, no logrará penetrar en la mentalidad de los hombres modernos». ${ }^{69}$

Para Mensaje el problema de la revolución era de forma sincrónica teológico y práctico, en términos de que la naturaleza de la acción política y la intervención social cristianas debía de ser clarificada en la inmediatez de las elecciones presidenciales de 1964, instancia en la cual se enfrentarían en lo fundamental dos alternativas: la transformación de inspiración marxista que postulaba el FRAP (Frente de Acción Popular) encabezado por el socialista Salvador Allende; o la «Revolución en Libertad» que proponía el Partido Demócrata Cristiano y su candidato Eduardo Frei Montalva. Así, a mediados de 1963 en las páginas de la revista jesuita se hacía una comparación entre la situación del FRAP y el PDC, indicándose que

67 Gorbea, J. «Revolución y evolución», en LV, 19 de mayo 1963, p. 16.

68 «Espiritual o nada», en LV, 26 de mayo 1963, p. 2.

69 Comblin, J. 1963. "¿Qué es una Misión?», TyV 4/2: 82-93. 
El revolucionarismo marxista del FRAP ve surgir, frente a sus consignas y objetivos -que podríamos llamar «tradicionales» en la revolución contemporánea- una nueva definición revolucionaria, no marxista y no violenta: la de la Democracia Cristiana. Esta sobrepasa rápidamente la etapa de una definición ideológica y se presenta como una fuerza política de primera magnitud; como fuerza sindical en pleno crecimiento, de decisiva importancia, y como movimiento estudiantil, juvenil, de pobladores y de mujeres, con perspectivas mayoritarias. Son los elementos clásicos de un movimiento popular revolucionario, y a ellos se juntan profesionales, técnicos y aun empresarios no vinculados con el régimen imperante, o en actitud de desvinculación, estos es, de una «intelectualidad» que abre las puertas desde el interior de la ciudadela. ${ }^{70}$

Como un indicador de la misma preocupación en torno a la eficacia política de la conceptualización cristiana de Revolución, casi un año después de haberse publicado el tan comentado número de Mensaje dedicado a la revolución en América Latina, la misma revista decidió centrar su edición de octubre de 1963 a la misma temática, pero esta vez referido a las «reformas revolucionarias» que el continente experimentaba. Como era de esperarse, desde la misma introducción al número se volvía sobre las polémicas generadas por la publicación de 1962, y los jesuitas reforzaban su elección de "revolución» como un término ajustado, así como los desafíos que implicaba la «cristianización» del concepto.

Así, para los redactores de Mensaje cristianizar la revolución era «algo substancial, como levadura suficientemente poderosa para transformar cualquier masa», suficiente para «despojarla de violencia injusta, de resentimientos, de odios y egoísmos; significaba no suprimir la libertad y los derechos del hombre sino, por el contrario, hacer que esa libertad y esos derechos no fuesen monopolio de una pequeña minoría sino se extendiesen a todos los latinoamericanos». Por ello, el concepto de revolución era a su juicio el más apropiado, y ello conscientes de todas las alternativas y matices que en el debate habían aparecido. Así, se preguntaba Mensaje, ¿era posible hablar de "evolución»? No, en tanto «la palabra evolución sugiere un cambio indeliberado, gradual y lento", la evolución era "un lujo que pueden permitirse los países 'desarrollados' y las clases poderosas, pero ¿qué sentido tiene para la inmensa mayoría?». El punto era que «el pueblo, y con razón, no cree en 'evoluciones' ni en 'consagraciones' vagas. Pide y exige un cambio radical, integral, rápido. No llamar a esto 'revolución' nos parece simplemente ceguera». Reiterando su confianza, los redactores insistían asimismo en que «el cristianismo es suficientemente poderoso y capaz de orientar y fecundar cualquier revolución», particularmente aquella que se «impone» y que podía ser «auténticamente cristiana, respetando, por consiguiente, todo lo que nuestras culturas y tradiciones tienen de positivo, pero que no se contentará con 'pseudo-órdenes' sino que se esforzará lealmente en acabar con falsedades, hipocresías e injusticias». Pues bien, el número de octubre de 1963 buscaba «indicar cuáles han de ser los contenidos y las formas de la 'revolución cristiana'». ${ }^{71}$

Nuevamente, será el jesuita belga Roger Vekemans el encargado de aportar considerable sustancia a esta

\footnotetext{
70 «Un esquema del futuro», en RM 120, julio 1963, pp. 283-284.

71 «Reformas revolucionarias en América Latina», en RM 123, octubre 1963, pp. 481-484.
}

definición, en este caso desde su posición de Director del Departamento de Elaboración de Modelos de DESAL y de la Escuela de Sociología de la Universidad Católica de Chile. En su reflexión, la reforma social era el núcleo del conjunto de las transformaciones, y ésta debía orientarse de acuerdo a los principios de la solidaridad y la subsidiariedad. A juicio del sacerdote, el primer paso debía ser dotar de un significado fuerte al concepto de reforma, con el fin de impedir que cayera «al desecho de la historia como una de tantas palabras traicionadas y despojadas de toda autenticidad», o peor aún, que la alusión a la realización de reformas se convirtiese en "una empresa dictatorial que impondrá a los pueblos esquemas forzados que no corresponden a las exigencias reales de su vida». Por ello, esta definición fuerte debía concebir a la reforma "como un esfuerzo para crear un sistema de convivencia» que permitiese «al hombre latinoamericano, fundado en principios racionales y morales, enfrentarse con toda realidad, objetividad y eficacia a esas nuevas circunstancias del mundo moderno ". ${ }^{72}$ Esta definición podía seguir siendo inoperante en caso de que -siempre a juicio de Vekemansno se la insuflara de los elementos que le darían vida y real eficacia: por una parte, el protagonismo del pueblo en su realización; por otra los principios, "la visión del mundo y del hombre» que inspiraran las reformas.

Con tal horizonte, el jesuita organizó su exposición otorgando el primado conceptual a la libertad, entendida como «la libertad esencial del hombre para autorrealizarse, para ser él mismo autor de su propia perfección y plenitud y para ser -considerado socialmente como 'pueblo'- el 'sujeto' y protagonista libre y solidario del progreso, del desarrollo, del cambio o como quiera que se llame su perfeccionamiento temporal». Este proceso de constitución social por la vía de la solidaridad -contrapuesta de forma evidente a las formas egoístas y competitivas propias del imaginario liberal- derivaba en la atribución legítima de la autoridad, cuya función específica era «actuar para suplir las deficiencias o corregir las desviaciones». Por ello, toda autoridad poseía el imperativo de la acción, y más allá de ello, era dueña de autonomía y soberanía. Pero, y este es el punto hacia el cual el autor que citamos centraba su análisis, al mismo tiempo que autónoma, «toda autoridad es subsidiaria, porque actúa en nombre de la solidaridad, en su resguardo, en su corrección, en su promoción y, en último término, en su suplencia, cuando las carencias de conciencia y libre responsabilidad solidaria no pueden ser salvadas de otro modo".

Así, la autoridad con función subsidiaria experimentaba un proceso de constitución "desde abajo», lo cual se verificaba de forma más expedita y sencilla en las comunidades pequeñas que en las grandes. Pero, y pese a lo anterior, la sociedad podía ser entendida -siempre de acuerdo a Ve-

72 Vekemans, R. "La reforma social, o la reforma de las reformas», en RM 123, octubre 1963, pp. 505-513. Debemos recordar aquí que Vekemans ya había tematizado el problema de las relaciones entre ideología, política y doctrina en los mismos términos, es decir, a partir del reconocimiento de las categorías objetivas de análisis e intervención sobre la realidad, que debían ser éticamente orientadas por la doctrina cristiana, que en ese ejercicio de tutela encontraría su profunda legitimidad de incidencia política. Vekemans, R. "Doctrina, ideología y política», RM 120, julio 1963, pp. 309-320. 
kemans- como el producto de la conexión natural que la solidaridad establecía entre «lo individual y particular o 'privado' y lo general, global, 'público'; entre el súbdito y la autoridad, entre el hombre y el poder». Producto de tales nexos, los sujetos se agruparían en "grupos intermedios» constituidos por «hombres orgánicamente agrupados por la solidaridad contenida en sus relaciones funcionales». Estos cuerpos intermedios formarían una "cadena jerárquica» cuya actividad se desarrollaba «desde las bases comunitarias hasta la cúspide, al encuentro de la autoridad». Todo lo anterior se traducía, en el esquema sociológico del belga, en el reconocimiento de que la acción reformadora en la sociedad debía de ser protagonizada, dinamizada a partir de estos cuerpos intermedios, que eran vistos como «el único camino verdaderamente democrático para todas las demás formas", y por ello a la hora de la aplicación política se debía contemplar la superación de las posibles contradicciones entre éstos y la autoridad, superación la cual no podía conseguirse «sino por la organización dinámica de la iniciativa popular para dar a la vigencia teórica de estos principios una aplicación práctica, y por la disposición de las autoridades centrales a la confianza, apoyo y promoción de las iniciativas populares del Bien Común». ${ }^{73}$

Es decir, y esto es lo que específicamente debemos consignar aquí, la opción por la reforma antes que por la revolución era para Vekemans una definición de profundo alcance conceptual, filosófico y sociológico, en tanto que la reforma-el cambio gradual enmarcado en la libertad y ajeno a la violencia y el antagonismo- era el fruto de la dinámica propia de la sociedad, en tanto entidad organizada a partir de los vínculos espontáneos a la vez que estructurales que la solidaridad como esencia ontológica tendía entre cada uno de sus miembros, en lo mediato articulados en grupos intermedios al servicio de los que se ponía de forma subsidiaria y vicaria una autoridad así legitimada. El modelo social del jesuita era por ello inmune al conflicto y la ruptura, ajeno a la radicalidad y la violencia, al control de grupos de presión o vanguardias no solo por motivos estrictamente políticos, sino por el comportamiento verificable de la sociedad en cuanto tal. Por ello, en síntesis, la revolución era destructiva de lo social en tanto que la reforma era su progresión esencialmente efectuada.

Es a partir de ese supuesto que se organizaron los capítulos temáticos del número de Mensaje de octubre de 1963: la reforma política, la reforma administrativa, la reforma fiscal, la reforma agraria, la educacional, etc. Sin embargo, al llegar al final del número, y sin duda a partir de las reacciones que había motivado la publicación de 1962, los redactores de la revista jesuita decidieron publicar un epílogo, en el cual se mostraron temerosos de que esta nueva contribución volviera a generar solo «palabras, palabras y palabras», y ratificaron su opción conceptual por revolución, por una «revolución cristiana» que se representaba como "continuadora de los grandes ideales del pasado y que procura encarnarlos en la realidad de hoy, profundizándolos y haciéndolos más puros a la luz de las experiencias adquiridas y de los progresos de la conciencia social». La clave de esta confianza en la revolución descansaba en un

\footnotetext{
73 Vekemans, R. "La reforma social, o la reforma de las reformas», en RM 123, octubre 1963, pp. 505-513.
}

fondo de creencia antropológica particular, y que generaba el optimismo jesuita ante el futuro: «la convicción de que el hombre no es un títere movido por los hilos ciegos de las leyes biológicas o de la necesidad histórica, sino un ser capaz de cooperar libremente con Dios e influir así en la creación del orden social en que desea vivir». Gracias a este factor, era posible observar cómo «el fermento cristiano presiona y golpea las conciencias y las estructuras mismas de la sociedad para que cese ya la opresión y florezcan las condiciones que permitan al hombre realizarse libremente». Al concluir, se sintetizaba el ánimo de todos los artículos publicados, en términos de considerar que «las reformas tendientes a conjugar la responsabilidad e iniciativa de los individuos y grupos intermedios con la función subsidiaria del Estado son la expresión estructurada del respeto que al cristiano merece la dignidad del hombre y su núcleo más valioso, la libertad $» .^{74}$ De esa forma, al menos en las páginas de Mensaje la conceptualización revolucionaria de la reforma, o viceversa, de un reformismo revolucionario, era sistemáticamente inscrita en la doble vertiente del accionar político estructural y la esperanza cristiana, entre la historia y la trascendencia, o como Vekemans rectoramente había establecido, entre la política, la ideología y la doctrina.

De esa forma, el giro que tomaba el concepto de revolución en la definición católica se relacionaba con la articulación de la candidatura democratacristiana, definida en lo fundamental por la consigna de «Revolución en Libertad» que sintetizaba de forma comprensiva y polémica buena parte del debate que hasta aquí hemos seguido, reivindicando así la profundidad de las transformaciones, como su intencionalidad ajena a la violencia y la radicalidad. En ese sentido, el hecho de que los cristianos y cristianas participasen en la posibilidad de lograr que utodos los chilenos» tuviesen "posibilidad de realizarse humana y plenamente» era una "verdadera revolución», pero "sin odios, sin rencores, sin venganzas, sin violencias, sin injusticias pero sincera e inquebrantablemente decidida a cambiar todo lo que sea necesario para lograr el bien de todos y no solo de clases, partidos o grupos». Haciendo en el fondo una fuerte crítica a las formas y procedimientos de la política en el Chile de su época, Mensaje postulaba -dos meses antes del triunfo de Eduardo Frei Montalva por una amplia mayoría de más del $56 \%$ de los votos-una Revolución que para ser efectivamente democrática requería

La plena y consciente participación de todos los chilenos. Una revolución impuesta desde arriba pasa a ser violencia y corre el serio peligro de traicionarse a sí misma y terminar siendo una dictadura más. No basta que la revolución, sincera o pretendidamente, se haga "para» los ciudadanos. Es necesario también que sea hecha "por» los ciudadanos. Esta revolución verdaderamente democrática exige un diálogo constante entre gobierno y ciudadanía y la organización permanente de ésta. Pero este diálogo será imposible si no se educa a los ciudadanos, si no se les hace ver la naturaleza, la trascendencia y las dificultades de los cambios que hay que realizar. A través de esta educación política los ciudadanos han de tomar conciencia de sus sordas aspiraciones de reforma, han de conocer las dificultades y asperezas del camino que lleva a ellos y han de sentir la importancia de su participación responsable. Una revolución que se limite a reemplazar el paternalismo

\footnotetext{
74 «Epílogo», en RM 123, octubre 1963, pp. 684-686.
} 
oligárquico por el paternalismo del Estado no será jamás democrática y está condenada a fracasar. ${ }^{75}$

\section{CONCLUSIONES}

Al finalizar, y a partir de los puntos aquí discutidos es posible extraer una serie de sintéticas conclusiones en torno al fenómeno de la conceptualización católica de la revolución en la primera parte de la década de 1960 en Chile. Así, en primer lugar, creemos que la productividad analítica del enfoque de la Historia Conceptual se ha demostrado significativa en este caso, en tanto ha sido posible aplicar categorías relevantes como politización y temporalización al uso estricto y contingente de un concepto, siendo éste reconocido por sus usuarios como un umbral histórico de realización y un campo de debate semántico, lo que de alguna forma confirma los presupuestos teórico metodológicos antes señalados.

En segundo lugar, y ya en un plano específicamente histórico, ha quedado demostrada la recurrencia del uso del concepto revolución por parte de agentes de opinión y pensamiento católico - de forma si se quiere más acentuada al interior del campo intelectual jesuitaen la coyuntura descrita, relevando este uso al menos dos factores importantes de subrayar aquí: su utilidad para dichos agentes como una herramienta semántica referible a la velocidad y dinámica del cambio histórico que diagnosticaban en Chile; así como la diversidad de reacciones que este uso implicó, dejándose en evidencia que una parte significativa del mundo católico experimentaba aprehensión tanto hacia el proceso que se desenvolvía, como a su caracterización como revolucionario. De forma complementaria, un segmento muy visible del pensamiento católico -particularmente vinculado al Arzobispado de Santiago y la Compañía de Jesús- argumentó a favor de la conceptualización revolucionaria, aun cuando ésta fuese a fin de cuentas matizada a partir de su significación en términos de "reforma", concepto que a fin de cuentas se asociaba con la realización de transformaciones estructurales pero sin el recurso a la violencia revolucionaria y su radicalidad, características ambas del uso marxista del concepto.

Finalmente, la eficacia histórica de la conceptualización aquí analizada quedó demostrada por el hecho de que, en primer lugar, aquellos sectores del pensamiento y la acción política-católicos o no-que divergieron en su percepción del contexto o el uso de revolución como un término asociable al cristianismo lo manifestaron pública y reiteradamente, confirmando así el papel de actor político relevante que jugaba la Iglesia católica y el pensamiento católico en el periodo. Más allá de ello, la victoria democratacristiana de 1964 bien puede ser interpretada como un testimonio de la incidencia efectiva que los planteamientos asociados al mundo católico progresista tuvieron no solo en las bases del PDC, sino que en el conjunto de la ciudadanía.

Todo ello, a fin de cuentas, permite amplificar el campo de acción tradicional de la opinión y el pensamiento católicos, y derivar en el planteamiento de que en el proceso de cambio histórico experimentado por la sociedad chilena a partir de la década de 1960, la esfera pública contenía proposiciones políticas sujetas a un proceso de intercambio y mixtura. Ejemplo de ello sería el uso cristiano de revolución, que en tanto concepto contingente y de matriz secular será dotado de significados trascendentes asociados a la lógica religiosa, invirtiendo de alguna forma la común dirección del proceso de secularización.

\section{BiBLIOGRAFÍA}

Arendt, H. 2004. Sobre la Revolución. Madrid: Alianza Editorial.

Beigel, F. 2011. Misión Santiago. El mundo académico jesuita y los inicios de la cooperación internacional católica. Santiago: LOM.

Blumenberg, H. 2008. La legitimación de la Edad Moderna. Valencia: Pre-Textos.

Bodeker, H. E. 2009. «Sobre el perfil metodológico de la historia conceptual». Historia y Grafía 32: 131-168.

Cabrera, M. A. 2001. Historia, Lenguaje y Teoría de la Sociedad. Valencia: Frónesis.

Compagnon, O. 2009. "Condiciones y paradojas de la recepción del pensamiento de Jacques Maritain en América Latina. Una perspectiva comparativa», en Touris, C. (Ed.), Dilemas del catolicismo contemporáneo en Europa y América Latina. Rosario: Prohistoria ediciones.

Delacroix, C.; Dosse, F. y García P. (editores) 2010. Historicidades. Buenos Aires: Waldhuter editores.

Escudier, A. 2010. “'Temporalización’ y modernidad política: intento de sistematización a partir de R. Koselleck», en F. Oncina (ed.), Palabras, conceptos, ideas. Estudios sobre historia conceptual. Barcelona: Herder.

Fernández, M. 2016a. «Cambio histórico, sociedad secular e Iglesia: interpretaciones del mundo católico ante un contexto de transformación. Chile, 1960-1964». Teología y Vida 57/1: 39-65.

Fernández, M. 2016b. «Puesto sobre la tierra pero con la mirada y los brazos hacia el cielo: la politización del laicado en Chile, 19601964». Revista Brasileira de Historia das Religioes 25: 239-270.

Fernández, M. 2016c. «Los hijos de las tinieblas son más sagaces que los hijos de la luz. Pensamiento político católico y marxismo en Chile, 1960-1964». Revista Izquierdas 28: 27-65.

Fernández Sebastián, J. (Director) 2009 y 2014. Diccionario político y social del mundo iberoamericano. Vols. I y II. Madrid: Fundación Carolina, Sociedad Estatal de Conmemoraciones Culturales, Centro de Estudios Políticos y Constitucionales.

Fichter, J. 1962. Cambio social en Chile. Un estudio de actitudes. Santiago de Chile: Editorial Universidad Católica.

Gamper, D. (Ed.) 2014. La fe en la ciudad secular. Laicidad y democracia. Madrid: Trotta.

Jay, M. 2009. Cantos de experiencia. Variaciones modernas sobre un tema universal. Buenos Aires: Paidós.

Koselleck, R. 2009. «Introducción al Diccionario Histórico de conceptos político-sociales básicos en lengua alemana». Anthropos 223: 333-358.

Löwy, M. 1999. Guerra de dioses. Religión y política en América Latina. México: Siglo XXI editores.

Millas, O. 1964. Los comunistas, los católicos y la libertad. Santiago: Editorial Austral.

Serrano, S. 2003. «Espacio público y espacio religioso en Chile republicano». Teología y Vida 44/2-3: 346-355.

Stuven, A. M. 2014. La religión en la esfera pública chilena:¿laicidad o secularización? Santiago de Chile: Ediciones UDP.

75 «Responsabilidad de los políticos», en RM 130, julio 1964, pp. 275-277. 